\title{
The origins and properties of intrinsic nonradiative recombination centers in wide bandgap GaN and AIGaN
}

S. F. Chichibu, A. Uedono, K. Kojima, H. Ikeda, K. Fujito, S. Takashima, M. Edo, K. Ueno, and S. Ishibashi

Citation: Journal of Applied Physics 123, 161413 (2018); doi: 10.1063/1.5012994

View online: https://doi.org/10.1063/1.5012994

View Table of Contents: http://aip.scitation.org/toc/jap/123/16

Published by the American Institute of Physics

\section{Articles you may be interested in}

The trap states in lightly Mg-doped GaN grown by MOVPE on a freestanding GaN substrate Journal of Applied Physics 123, 161405 (2018); 10.1063/1.5010849

Large electron capture-cross-section of the major nonradiative recombination centers in Mg-doped GaN epilayers grown on a GaN substrate

Applied Physics Letters 112, 211901 (2018); 10.1063/1.5030645

Thermal quenching of the yellow luminescence in GaN

Journal of Applied Physics 123, 161520 (2018); 10.1063/1.4995275

Recombination properties of dislocations in GaN

Journal of Applied Physics 123, 161543 (2018); 10.1063/1.4995580

Perspective: Toward efficient GaN-based red light emitting diodes using europium doping Journal of Applied Physics 123, 160901 (2018); 10.1063/1.5010762

Luminescence properties of defects in GaN

Journal of Applied Physics 97, 061301 (2005); 10.1063/1.1868059

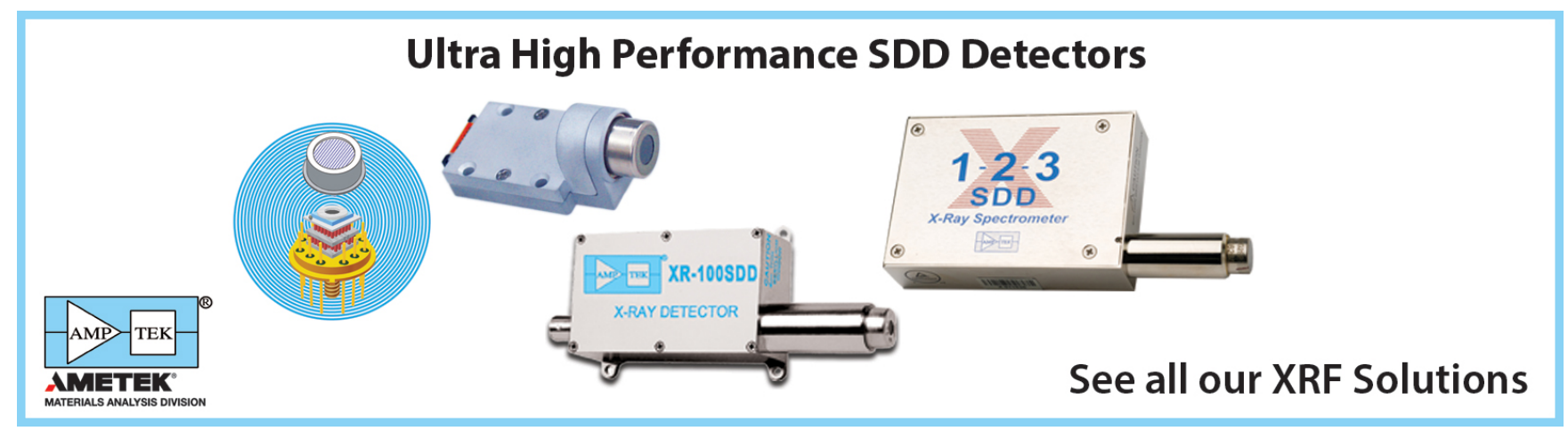




\title{
The origins and properties of intrinsic nonradiative recombination centers in wide bandgap GaN and AIGaN
}

\author{
S. F. Chichibu, ${ }^{1,2, a)}$ A. Uedono, ${ }^{3}$ K. Kojima, ${ }^{1}$ H. Ikeda, ${ }^{4}$ K. Fujito, ${ }^{4}$ S. Takashima,${ }^{5}$ M. Edo, ${ }^{5}$ \\ K. Ueno, ${ }^{5}$ and S. Ishibashi ${ }^{6}$ \\ ${ }^{1}$ Institute of Multidisciplinary Research for Advanced Materials, Tohoku University, Sendai 980-8577, Japan \\ ${ }^{2}$ Institute of Materials and Systems for Sustainability, Nagoya University, Furo-cho, Chikusa 464-8603, Japan \\ ${ }^{3}$ Division of Applied Physics, Faculty of Pure and Applied Sciences, University of Tsukuba, Tsukuba 305-8573, \\ Japan \\ ${ }^{4}$ LED Materials Department, Mitsubishi Chemical Corporation, Ushiku, Tsukuba 300-1295, Japan \\ ${ }^{5}$ Advanced Technology Laboratory, Fuji Electric Co., Ltd., Hino, Tokyo 191-8502, Japan \\ ${ }^{6}$ Research Center for Computational Design of Advanced Functional Materials, National Institute of Advanced \\ Industrial Science and Technology, Tsukuba, Ibaraki 305-8568, Japan
}

(Received 9 November 2017; accepted 21 February 2018; published online 14 March 2018)

\begin{abstract}
The nonradiative lifetime $\left(\tau_{\mathrm{NR}}\right)$ of the near-band-edge emission in various quality GaN samples is compared with the results of positron annihilation measurement, in order to identify the origin and to determine the capture-cross-section of the major intrinsic nonradiative recombination centers (NRCs). The room-temperature $\tau_{\mathrm{NR}}$ of various n-type $\mathrm{GaN}$ samples increased with decreasing the concentration of divacancies composed of a Ga vacancy $\left(\mathrm{V}_{\mathrm{Ga}}\right)$ and a $\mathrm{N}$ vacancy $\left(\mathrm{V}_{\mathrm{N}}\right)$, namely, $\mathrm{V}_{\mathrm{Ga}} \mathrm{V}_{\mathrm{N}}$. The $\tau_{\mathrm{NR}}$ value also increased with increasing the diffusion length of positrons, which is almost proportional to the inverse third root of the gross concentration of all point defects. The results indicate that major intrinsic NRC in n-type $\mathrm{GaN}$ is $\mathrm{V}_{\mathrm{Ga}} \mathrm{V}_{\mathrm{N}}$. From the relationship between its concentration and $\tau_{\mathrm{NR}}$, its hole capture-cross-section is estimated to be about $7 \times 10^{-14} \mathrm{~cm}^{2}$. Different from the case of $4 \mathrm{H}-\mathrm{SiC}$, the major NRCs in p-type and n-type GaN are different: the major NRCs in $\mathrm{Mg}$-doped p-type $\mathrm{GaN}$ epilayers are assigned to multiple vacancies containing a $\mathrm{V}_{\mathrm{Ga}}$ and two (or three) $\mathrm{V}_{\mathrm{N}} \mathrm{s}$, namely, $\mathrm{V}_{\mathrm{Ga}}\left(\mathrm{V}_{\mathrm{N}}\right)_{n}(n=2$ or 3 ). The ion-implanted $\mathrm{Mg}$ doped $\mathrm{GaN}$ films are found to contain larger size vacancy complexes such as $\left(\mathrm{V}_{\mathrm{Ga}}\right)_{3}\left(\mathrm{~V}_{\mathrm{N}}\right)_{3}$. In analogy with $\mathrm{GaN}$, major NRCs in $\mathrm{Al}_{0.6} \mathrm{Ga}_{0.4} \mathrm{~N}$ alloys are assigned to vacancy complexes containing an $\mathrm{Al}$ vacancy or a $\mathrm{V}_{\mathrm{Ga}}$. Published by AIP Publishing. https://doi.org/10.1063/1.5012994
\end{abstract}

\section{INTRODUCTION}

For solving the energy crisis problem, the exploitation of energy-saving high-power electronic devices operating at high frequencies, as well as the present solid-state lighting using high efficiency light-emitting diodes (LEDs), is one of the significant ways of markedly decreasing total energy consumption. Gallium nitride $(\mathrm{GaN})$ and related $(\mathrm{Al}, \mathrm{Ga}, \mathrm{In}) \mathrm{N}$ alloys are a suitable candidate material system for this purpose because they provide practical benefits in the production of LEDs and laser diodes (LDs) operating in the ultraviolet (UV) to green wavelengths and white LEDs consisting of an InGaN quantum well (QW) blue LED and yellow phosphors. ${ }^{1}$ We note that such LEDs are fabricated on a heteroepitaxial GaN film grown on $c$-plane $\mathrm{Al}_{2} \mathrm{O}_{3}$ substrates, generally abbreviated as "GaN template" and therefore contain high density of threading dislocations (TDs) of the order of $10^{8}$ to $10^{9} \mathrm{~cm}^{-2}$. Because such high threading dislocation density (TDD) InGaN QWs have been exhibiting sufficiently high near-band-edge (NBE) emission intensity with the aid of defect- ${ }^{1-4}$ and polarization field ${ }^{1,2,4}$ resistant radiation probability of the localized excitons in InGaN alloys, the development of a low TDD bulk freestanding (FS) GaN substrate took a long time.

${ }^{a)}$ E-mail: chichibulab@yahoo.co.jp
On another front, GaN has a potential to realize highpower electronic devices operating at high frequencies ${ }^{5}$ owing to its outstanding characteristics, including large bandgap energy $\left(E_{\mathrm{g}}\right)$, high break-down field, and high saturation velocity. Indeed, a normally off vertical GaN-based transistor on a FS-GaN substrate with a low specific on-state resistance $\left(R_{\mathrm{ON}}\right)$ of $1 \mathrm{~m} \Omega \cdot \mathrm{cm}^{2}$ and a high off-state breakdown voltage $\left(V_{\mathrm{BD}}\right)$ of $1.7 \mathrm{kV}$ has been demonstrated by using a p-type GaN/unintentionally doped (UID) AlGaN/ $\mathrm{GaN}$ heterostructure overgrown on the $\mathrm{V}$-shaped grooves formed over the drift layer. ${ }^{6}$ However, further improvements in the device performances including the stability and reliability are mandatory for integrating GaN power devices in commercial systems. For this purpose, large-area, singledomain, mosaic- or bowing-free FS-GaN wafers with a negligible TDD are essential. In particular for fabricating vertically current-flowing devices, precisely controlled building blocks such as low-resistivity FS-GaN substrates with negligible lattice mismatch to overlayers, very low impurity concentration n-type drift layer, and structured n-type and ptype segments on their top are required.

For designing such advanced optical and electronic devices based on $\mathrm{GaN}$, in-depth probing and control of the carrier lifetime in the constituent layers are essential. Especially, controlling the minority carrier lifetime $\left(\tau_{\text {minority }}\right)$ is indispensable because it reflects carrier recombination 
lifetime and determines the carrier diffusion length and eventually determines the device performances. For example, $\tau_{\text {minority }}$ limits the switching speed of insulating-gate bipolar transistors: as the energy loss of power-switching devices is a sum of $R_{\mathrm{ON}}$ and switching-loss, low $R_{\mathrm{ON}}$ and appropriate $\tau_{\text {minority }}$ are simultaneously required. Also, $\tau_{\text {minority }}$ is important for unipolar devices like Schottky barrier diodes. In the case of a direct bandgap semiconductor GaN, $\tau_{\text {minority }}$ can be measured by using time-resolved photoluminescence (TRPL) measurement under low-excitation conditions. ${ }^{4}$ The photoluminescence $(\mathrm{PL})$ lifetime $\left(\tau_{\mathrm{PL}}\right)$ of the NBE emission is equal to $\tau_{\text {minority }}$ and is expressed by

$$
\tau_{P L}^{-1}=\tau_{R}^{-1}+\tau_{N R}^{-1},
$$

where $\tau_{\mathrm{R}}$ and $\tau_{\mathrm{NR}}$ are the radiative and nonradiative recombination lifetimes, respectively. Here, $\tau_{\mathrm{R}}$ is inverse of the radiative recombination rate $\left(R_{\mathrm{R}}\right)$ and reflects the radiative performance of the material. Accordingly, $\tau_{\mathrm{R}}$ of a homogeneous semiconductor material, which has zero inhomogeneous broadening, is unique to the material when there is no quantum confinement. On the other hand, $\tau_{\mathrm{NR}}$ is inverse of the nonradiative recombination rate $\left(R_{\mathrm{NR}}\right)$ and therefore inversely proportional to the product of the capture rate and concentration of Shockley-Read-Hall (SRH)-type midgap nonradiative recombination centers (NRCs) $\left(C_{\mathrm{NRC}}\right.$ and $N_{\text {NRC }}$, respectively);

$$
\tau_{N R}=R_{N R}^{-1}=\frac{1}{C_{N R C} \cdot N_{N R C}} .
$$

These parameters are quite important, since they determine the internal quantum efficiency $\left(\eta_{\text {int }}\right)$ of the NBE emission under the relation

$$
\eta_{\mathrm{int}}=\frac{R_{\mathrm{R}}}{\left(R_{\mathrm{R}}+R_{\mathrm{NR}}\right)}=\frac{1}{1+\frac{\tau_{\mathrm{R}}}{\tau_{\mathrm{NR}}}} .
$$

The relationship among the generation rate $(G)$ by a photon $(h \nu)$, radiative recombination, and nonradiative recombination is schematically shown in Fig. 1(a). The role of a NRC with the minority carrier capture-cross-section, $\sigma$, and a minority carrier with the thermal velocity, $v_{\text {th }}$, is schematically shown in Fig. 1(b). Here, $C_{\mathrm{NRC}}=\sigma \cdot v_{t h}$. Accordingly, long $\tau_{\mathrm{NR}}$ is preferred for optical devices such as LEDs, LDs, and solar cells. Long $\tau_{\mathrm{NR}}$ is also required for high $V_{\mathrm{BD}}$ power devices because NRCs are the cause of recombination and generation currents and hence eventually lower $V_{\mathrm{BD}}$.

As described above, $N_{\text {NRC }}$ should be minimized in such devices. The accurate understanding of the origins and properties of major intrinsic NRCs, which most likely originate from native point defects, is a universal protocol for developing a technique to decrease them and consequently improve the device performances. There exist plenty of sources for NRCs such as large structural defects like voids and cracks, TDs with edge, screw, or mixed components, surface defects causing the surface recombination, and SRH-type deep levels (DLs). We note that Auger recombination is a nonradiative recombination process owing to

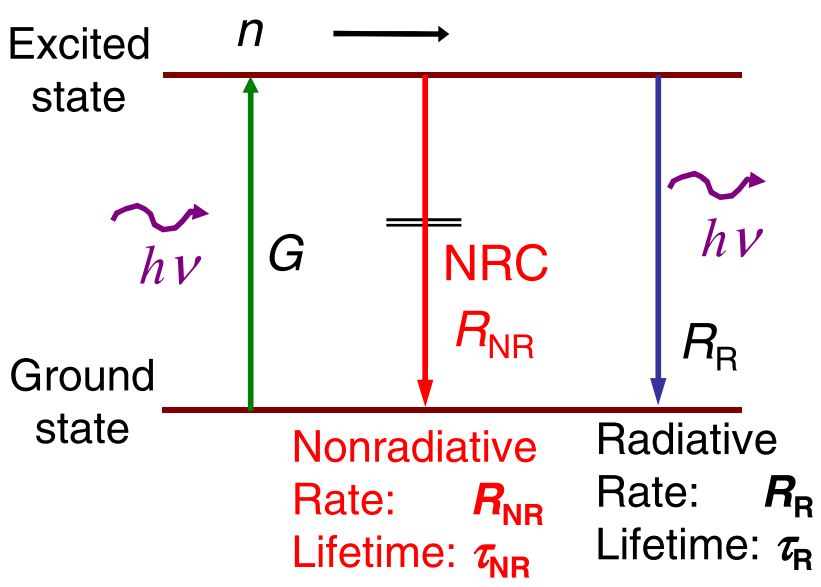

(a)

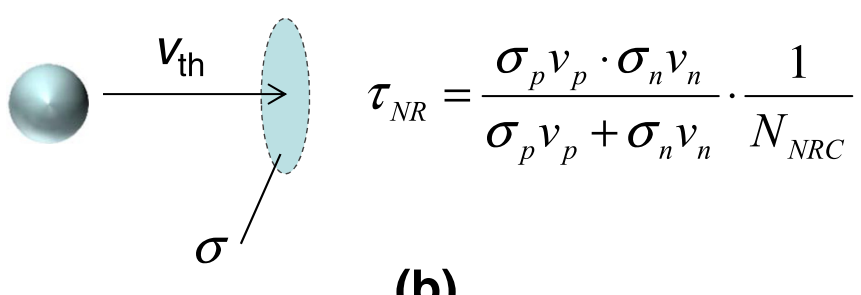

(b)

FIG. 1. (a) Schematic representation of the relationship among the generation of an electron-hole pair or an exciton by a photon $h \nu$ with the rate $G$, nonradiative recombination at a SRH-type NRC with the rate $R_{\mathrm{NR}}$ (lifetime $\tau_{\mathrm{NR}}$ ), and radiative recombination with the rate $R_{\mathrm{R}}$ (lifetime $\tau_{\mathrm{R}}$ ). (b) Schematic model of a NRC capturing minority carriers of a thermal velocity $v_{\text {th }}$ and the capture-cross-section $\sigma$. In the case of n-type GaN, in which minority carriers are holes, $\tau_{\mathrm{NR}}$ is expressed by $\frac{1}{\sigma_{p} \cdot v_{t h} \cdot N_{N R C}}$.

different mechanisms. With respect to $(\mathrm{Al}, \mathrm{In}, \mathrm{Ga}) \mathrm{N}$ epilayers and QWs, TDs had long been invoked to as the dominant NRCs to limit $\eta_{\text {int }}$ of the NBE emission, ${ }^{7}$ as the NBE emission intensity of $\mathrm{GaN}$ generally increased with the decrease in TDD. ${ }^{1,7}$ However, as the authors have been suggesting based on the results of TRPL and positron $\left(\mathrm{e}^{+}\right)$ annihilation spectroscopy (PAS) ${ }^{8-11}$ measurements since 2005 (Ref. 12), point defect complexes containing a Ga vacancy $\left(\mathrm{V}_{\mathrm{Ga}}\right)$ are the most likely true origin of predominant intrinsic NRCs in GaN, ${ }^{12,13}$ because $\tau_{\mathrm{PL}}$ at room temperature, which nearly reflects $\tau_{\mathrm{NR}}$, decreases with increasing the concentration of $\mathrm{V}_{\mathrm{Ga}}$ defects $\left(\left[\mathrm{V}_{\mathrm{Ga}}\right]\right)$. We note that the importance of $\mathrm{V}_{\mathrm{Ga}} \mathrm{S}$ for the broad luminescence band at around $2.2 \mathrm{eV}$, which is called as "yellow luminescence (YL) band,"14-16 and the nonradiative recombination has been speculated ${ }^{17,18}$ earlier than 2005. Although experimental evidence has not been presented for the presence of $\mathrm{V}_{\mathrm{Ga}} \mathrm{s}$. Our assignment ${ }^{12,13}$ is essentially consistent with the calculated results ${ }^{15,19,20}$ that the formation energy ( $E_{\text {Form }}$ ) of negatively charged defects such as $\mathrm{V}_{\mathrm{Ga}} \mathrm{s}$ in wide bandgap semiconductors like GaN can become smaller due to the Fermi level $\left(E_{\mathrm{F}}\right)$ term $\left(+q E_{\mathrm{F}}\right) \cdot{ }^{15,19,20}$ In analogy with the results for $\mathrm{GaN}^{12,13}$ the authors have assigned ${ }^{21}$ point defect complexes containing a cation vacancy $\left(\mathrm{V}_{\mathrm{III}}\right)$ as the origin of dominant intrinsic NRCs in $\mathrm{Al}_{0.6} \mathrm{Ga}_{0.4} \mathrm{~N}$ epilayers grown by metalorganic vapor phase epitaxy (MOVPE). We 
note that $E_{\mathrm{Form}}$ of an $\mathrm{Al}$ vacancy $\left(\mathrm{V}_{\mathrm{Al}}\right)$ in $\mathrm{AlN}$ has been calculated to have negative value in n-type AlN. ${ }^{20,22,23}$

In the previous reports, ${ }^{12,13,21}$ the authors have used complementary TRPL and PAS ${ }^{8-11}$ measurements to correlate $\tau_{\mathrm{NR}}$ at room temperature and the concentration of $\mathrm{V}_{\mathrm{III}}$ $\left(\left[\mathrm{V}_{\mathrm{III}}\right]\right) . \mathrm{PAS}^{8-11}$ is an established, nondestructive, and exclusive tool to detect negatively charged and neutral vacancy defects in a semiconductor. $\mathrm{A} \mathrm{e}^{+}$is an antimatter of an electron $\left(\mathrm{e}^{-}\right)$and has a positive charge with a mass identical to $\mathrm{e}^{-}$. When a $\mathrm{e}^{+}$is implanted into condensed matter, it annihilates with a surrounding $\mathrm{e}^{-}$and emits two $511 \mathrm{keV} \gamma$-rays according to $E_{\gamma}=m c^{2}$, where $E_{\gamma}$ is the energy, $m$ is the mass, and $c$ is the speed of the light. The annihilating $\gamma$-ray spectra are broadened in energy due to the momentum component of the annihilating positron-electron $\left(\mathrm{e}^{+}-\mathrm{e}^{-}\right)$pair $p_{\mathrm{L}}$, which is parallel to the direction of the $\gamma$-rays. The energy of the $\gamma$ rays is given by the relation $E_{\gamma}=m c^{2} \pm \Delta E_{\gamma} \mathrm{keV}$. The Doppler shift $\Delta E_{\gamma}$ is given by the relation $\Delta E_{\gamma}=p_{\mathrm{L}} c / 2$. A freely diffusing $\mathrm{e}^{+}$likely localize in a vacancy-type defect because of the Coulomb repulsion from ion cores. Because the momentum distribution of $\mathrm{e}^{-}$surrounding such defects is smaller than that in defect-free (DF) regions, the defects can be detected by measuring the Doppler broadening spectra of the annihilation radiation. The resulting change in the $\gamma$-ray spectra is characterized by the line-shape parameter $S$ and the wing parameter $W$, where the former mainly reflects the fraction of annihilating $\mathrm{e}^{+}-\mathrm{e}^{-}$pairs of small momentum distribution (mostly valence electrons) and the latter represents the fraction of the pairs of large momentum distribution (mostly core electrons). Since $\mathrm{V}_{\mathrm{Ga}} \mathrm{s}$ and their complexes are acceptor-type defects in $\mathrm{GaN}$, they are the most probable candidates of $\mathrm{e}^{+}$trapping centers. ${ }^{10,11}$ Accordingly, $S$ and $W$ can be used as a measure of size and/or concentration of negatively charged $\mathrm{V}_{\mathrm{Ga}} \mathrm{S}$ and $\mathrm{V}_{\mathrm{Ga}^{-} \text {-complexes. For epitaxial }}$ structures, characteristic $S$ and positron diffusion length $\left(L_{+}\right)$ in each layer can be determined by using a monoenergetic $\mathrm{e}^{+}$-beam, ${ }^{9-11}$ by which the mean implantation depth of $\mathrm{e}^{+}$ can be controlled. The analysis ${ }^{24}$ involves solving the diffusion equation of $\mathrm{e}^{+}$as a function of acceleration energy $E$ using the initial implantation profile. Here, $L_{+}$can be used as a measure of gross concentration of $\mathrm{e}^{+}$trapping centers and scattering centers, because both of them shorten $L_{+}$. In a three-dimensional (3D) space, $L_{+}$may correspond to an inverse third root of gross point defect concentration. The scattering centers are positively charged and neutral point defects such as $\mathrm{N}$ vacancies $\left(\mathrm{V}_{\mathrm{N}} \mathrm{s}\right)$, interstitials $\left(\mathrm{Ga}_{\mathrm{i}}\right.$ and $\left.\mathrm{N}_{\mathrm{i}}\right)$, and certain complexes.

In this article, we review our knowledge on the origin and properties of major intrinsic NRCs in GaN. The $\tau_{\mathrm{NR}}$ value of the NBE emission, which mostly represents $\tau_{\text {minority }}$, in various quality GaN samples measured using TRPL is correlated with the results of PAS measurement, in order to assign the origin and determine $\sigma$ of the major intrinsic NRCs. The room-temperature $\tau_{\mathrm{NR}}$ in n-type GaN of a variety of TDD, growth orientations, polar directions, and polytypes, which were grown by various growth techniques, increased with the decrease in the concentration of divacancies composed of a $\mathrm{V}_{\mathrm{Ga}}$ and a $\mathrm{V}_{\mathrm{N}}\left(\left[\mathrm{V}_{\mathrm{Ga}} \mathrm{V}_{\mathrm{N}}\right]\right)$. The $\tau_{\mathrm{NR}}$ value also increased with increasing $L_{+}$, and these results indicate that major intrinsic NRCs in GaN is $\mathrm{V}_{\mathrm{Ga}} \mathrm{V}_{\mathrm{N}}$. From the relationship between $\tau_{\mathrm{NR}}$ and $N_{\mathrm{NRC}}$, its hole capture-cross-section $\left(\sigma_{\mathrm{p}}\right)$ is determined to be $7 \times 10^{-14} \mathrm{~cm}^{2}$. The major NRCs in the epitaxial and ion-implanted (I/I) Mg-doped GaN films are assigned to larger size multiple vacancy complexes such as $\left(\mathrm{V}_{\mathrm{Ga}}\right)_{3}\left(\mathrm{~V}_{\mathrm{N}}\right)_{3}$. In analogy with $\mathrm{GaN}$, major NRCs in $\mathrm{Al}_{0.6} \mathrm{Ga}_{0.4} \mathrm{~N}$ alloys are assigned to vacancy complexes containing $\mathrm{V}_{\mathrm{III}}$.

\section{EXPERIMENTAL}

\section{A. GaN samples}

For drawing relationships between $\tau_{\text {minority }}$ and $S(\tau-S)$ and $\tau_{\text {minority }}$ and $L_{+}\left(\tau-L_{+}\right)$, various quality n-type GaN samples were prepared. They were (i) $80-\mu \mathrm{m}$-thick $c$-plane UID FS-GaN grown by MOVPE using the lateral epitaxial overgrowth (LEO) technique on a GaN template followed by polishing away the substrate [the sample identification (ID) name is abbreviated as MOVPE FS-GaN], ${ }^{12}$ (ii) 1 - and 5 - $\mu$ m-thick UID Ga-polar $c$-plane GaN grown by MOVPE on a $c$-plane $\mathrm{Al}_{2} \mathrm{O}_{3}$ [abbreviated as uid $+\mathrm{c}(1)$ and uid $+\mathrm{c}(5)$, respectively], ${ }^{12}$ (iii) $0.7-\mu \mathrm{m}$-thick unintentionally O-doped $(n=5$ $\times 10^{18} \mathrm{~cm}^{-3}$ ) N-polar $c$-plane GaN grown by MOVPE on a $c$-plane $\mathrm{Al}_{2} \mathrm{O}_{3}$ (uid -c), ${ }^{12}$ (iv) 2- $\mu$ m-thick Si-doped $c$-plane $\mathrm{GaN}$ on a $c$-plane $\mathrm{Al}_{2} \mathrm{O}_{3}$ [Si-doped (1.6), Si-doped (1.9), and Si-doped (2.2), of which doping concentrations were the numbers in parentheses time $\left.10^{18} \mathrm{~cm}^{-3}\right],{ }^{11}$ (v) $1-\mu \mathrm{m}$-thick unintentionally O-doped $\left(\geq 10^{18} \mathrm{~cm}^{-3}\right)$ cubic zinc blende (001) GaN grown by MOVPE on (001) GaAs with or without $\mathrm{AlGaN} / \mathrm{GaN}$ superlattice buffer layer $[\mathrm{ZB}($ no $\mathrm{SL})$ and $\mathrm{ZB}(\mathrm{SL})],{ }^{12}$ (vi) $1-\mu \mathrm{m}$-thick unintentionally O-doped (001) GaN grown by $\mathrm{N}_{2}$ rf-plasma-assisted molecular-beam epitaxy (MBE) on (001) 3C-SiC with AlN/GaN multiple buffer layer [ZB(MBE)], ${ }^{12}$ (vii) $15-16-\mu$ m-thick UID $a$-plane GaN grown by hydride vapor phase epitaxy (HVPE) on $r$-plane $\mathrm{Al}_{2} \mathrm{O}_{3}$ with or without LEO-GaN base $\left[a-\mathrm{GaN}(\mathrm{LEO})\right.$ and $a$-GaN],${ }^{12}$ and (viii) unintentionally O-doped $\left(4 \times 10^{18} \mathrm{~cm}^{-3}\right) \mathrm{m}$-plane FS-GaN grown by HVPE on a $\mathrm{LiAlO}_{2}$ substrate followed by delamination $(m-\mathrm{GaN}) .^{12}$ The TDD in these samples was varied between $10^{5}$ and $10^{10} \mathrm{~cm}^{-2}$ (Ref. 12).

Another low TDD FS-GaN sample ${ }^{25,26}$ was grown using vertical-flow HVPE apparatus. ${ }^{25}$ At first, approximately $1-\mathrm{cm}-$ thick, transparent $c$-plane $\mathrm{GaN}$ boules were grown on a c-plane $\mathrm{Al}_{2} \mathrm{O}_{3}$. Appropriate amount of gaseous $\mathrm{HCl}$ was flowed on heated $\mathrm{Ga}$, and $\mathrm{NH}_{3}$ was supplied from a separate gas line. Typical growth temperature and pressure were $1050{ }^{\circ} \mathrm{C}$ and atmospheric pressure, respectively. The growth duration was varied from 55 to $96 \mathrm{~h}$. Approximately $325-\mu \mathrm{m}-$ thick, $10 \times 10-\mathrm{mm}^{2}$-area, $c$ - or $m$-plane FS-GaN wafers were sliced $^{25,26}$ from such boules grown under various conditions. The surface of the wafers was polished with chemical treatment. Details of the growth and fundamental properties have been given in Refs. 25 and 26. The $c$-plane UID samples were abbreviated as $\mathrm{C} 0, \mathrm{C} 1, \mathrm{C} 2$, and $\mathrm{C} 3$, and Si-doped sample was named $\mathrm{C} 4$. The $m$-plane UID sample was abbreviated by M1: their electrical and optical properties are given in Ref. 13. In addition, an n-type low-resistivity $\left(\rho=8.5 \times 10^{-3} \Omega \mathrm{cm}\right)$, very low TDD $\left(\sim 10^{4} \mathrm{~cm}^{-2}\right) \mathrm{m}$-plane FS-GaN wafer ${ }^{27}$ named M2 was grown by HVPE on a nearly bowing-free bulk GaN 
seed wafer, which was synthesized by the ammonothermal (AT) method in supercritical ammonia using an acidic mineralizer. $^{28}$ We note that particular AT method used by Mitsubishi Chemical Corporation is named supercritical acidic ammonia technology (SCAAT $\left.{ }^{\mathrm{TM}}\right){ }^{28}$ The structural, electrical, and optical properties of M2 are given in Refs. 27 and 29.

All samples described above were n-type GaN. For evaluating the major defect species ${ }^{30,31}$ and their influences on the optical properties ${ }^{32}$ in p-type $\mathrm{GaN}$, epitaxial and $\mathrm{I} / \mathrm{I} \mathrm{Mg-}$ doped $\mathrm{GaN}$ (GaN:Mg) samples were prepared. ${ }^{30,31}$ Approximately 1- $\mu$ m-thick GaN:Mg epilayers were grown on a 4 - $\mu$ m-thick UID GaN epilayer grown on a $c$-plane FSGaN substrate grown by HVPE. Potential influences of TDs on the PL properties may be minimized, as TDD of the substrate used was in the range of $10^{6} \mathrm{~cm}^{-2}$. The $\mathrm{Mg}$ concentrations, $\left[\mathrm{Mg}\right.$ ], were $5 \times 10^{17}, 2 \times 10^{18}$, and $4 \times 10^{19} \mathrm{~cm}^{-3}$. For the I/I samples, $\mathrm{Mg}^{+}$ions were implanted into the same 4$\mu$ m-thick UID GaN film with several energies ranging from 20 to $430 \mathrm{keV}$, in order to form a 500 -nm-thick box-profile with $[\mathrm{Mg}]$ of $1 \times 10^{17}, 1 \times 10^{18}$, and $1 \times 10^{19} \mathrm{~cm}^{-3}$. The I/I was carried out at room temperature and followed by the deposition of a 300-nm-thick AlN decomposition-shield by a sputtering method. The samples were annealed at $1300^{\circ} \mathrm{C}$ for $5 \mathrm{~min}$ in $\mathrm{N}_{2}$ gas at atmospheric pressure. The decomposition-shield was chemically removed after annealing. The sample details are given in Ref. 32.

For discussing the major intrinsic $\mathrm{NRCs}^{21}$ in $\mathrm{Al}_{0.6} \mathrm{Ga}_{0.4} \mathrm{~N}$ alloy films, approximately $0.8-\mu \mathrm{m}$-thick, Si-doped $c$-plane $\mathrm{Al}_{0.6} \mathrm{Ga}_{0.4} \mathrm{~N}$ epitaxial films $\left(\mathrm{Al}_{0.6} \mathrm{Ga}_{0.4} \mathrm{~N}: \mathrm{Si}\right)$ were grown at $6.7 \times 10^{3} \mathrm{~Pa}$ by MOVPE on a $0.8-\mu$ m-thick AlN template, which was grown on a $c$-plane $\mathrm{Al}_{2} \mathrm{O}_{3}$ substrate. The $\mathrm{Si}$ concentration ([Si]) in the solid-phase was varied from $2 \times 10^{16}$ to $4 \times 10^{18} \mathrm{~cm}^{-3}$. The TDD having edge components $\left(N_{\mathrm{E}}\right)$ was estimated to be about $3 \times 10^{8} \mathrm{~cm}^{-2}$. Details of the growth conditions are given in Ref. 33 .

\section{B. Steady-state, time-resolved, and spatio-time- resolved luminescence measurements}

For macroarea measurements, steady-state PL of GaN was excited using the $325.0 \mathrm{~nm}$ line of a cw He-Cd laser with the power density of $20 \mathrm{~W} \cdot \mathrm{cm}^{-2}$. For TRPL measurement, the NBE PL was excited using approximately $200 \mathrm{fs}$ pulses of a frequency-tripled $(3 \omega)$ mode-locked $\mathrm{Al}_{2} \mathrm{O}_{3}$ :Ti laser operating at $80 \mathrm{MHz}$. The $3 \omega$ wavelength was approximately $267 \mathrm{~nm}$. The excitation density was approximately $125 \mathrm{~nJ}$ $\mathrm{cm}^{-2}$ (per pulse), in order to ensure weak-excitation conditions. ${ }^{4}$ The spot diameter and estimated excited carrier concentration were $1 \mathrm{~mm}$ and a few times $10^{16} \mathrm{~cm}^{-3}$, respectively, when $\tau_{\mathrm{PL}}$ is $1 \mathrm{~ns}$. The reason why both PL and TRPL were carried out under weak-excitation regime is to underline the nonradiative recombination processes in these materials. Because most of FS-GaN samples exhibited relatively long luminescence decay, the pulse repetition rate was reduced down to $8 \mathrm{MHz}$ or $0.8 \mathrm{MHz}$ using a pulse picker. The TRPL signal was collected using a standard streak camera. The TRPL signals were fitted using a single- or bi-exponential line shape function: $I(t)=A_{1} \exp \left(-t / \tau_{1}\right)$
$+A_{2} \exp \left(-t / \tau_{2}\right)$, where $I(t)$ is the intensity at time $t$ and $A_{1}$ $\left(A_{2}\right)$ and $\tau_{1}\left(\tau_{2}\right)$ are the pre-exponential constant and the lifetime, respectively, of the fast (slow) decay component. The value of $\tau_{1}$, which mostly limits the cw PL intensity at room temperature, is used as the representative $\tau_{\mathrm{PL}}$.

As described in Sec. I, $\tau_{\mathrm{NR}}$ and $\tau_{\mathrm{R}}$ can be obtained by using Eqs. (1) and (3). Therefore, experimental values of $\tau_{\mathrm{PL}}$ and $\eta_{\text {int }}$ are required to obtain $\tau_{\mathrm{NR}}$. As depicted in Fig. 1(b), the nonradiative recombination eventually occurs when a minority carrier (or an exciton) is captured by a NRC having characteristic $\sigma$. In the case of n-type $\mathrm{GaN}, \mathrm{e}^{-}$is already captured by a NRC and the hole capture-cross-section $\sigma_{\mathrm{p}}$ limits this event. Because $v_{\text {th }}$ of a hole, $v_{\mathrm{p}}$, is $\sqrt{\frac{3 k_{\mathrm{B}} T}{m_{\mathrm{p}}}}$, where $k_{\mathrm{B}}$ is the Boltzmann constant, $T$ is the temperature, and $m_{\mathrm{p}}$ is the hole effective mass, finite $T$ is necessary for a hole to gain a thermal velocity. Accordingly, $\eta_{\text {int }}$ at $0 \mathrm{~K}$ in principle becomes unity when average distance of NRCs is far longer than the exciton Bohr diameter $\left(2 a_{\mathrm{B}}\right)$ and excitons do not move (zero carrier temperature). However, when $N_{\mathrm{NRC}}$ exceeds the critical value, $\eta_{\text {int }}$ at $0 \mathrm{~K}$ is no longer unity, because an electronhole pair or an exciton recombines at NRCs without diffusion or drift. The probability that a diffusion-free $(0 \mathrm{~K})$ exciton is not captured by NRCs but decays with radiative recombination, which is defined ${ }^{34}$ by

$$
\eta_{\mathrm{int}}^{\max }=1-\frac{4}{3} \pi a_{\mathrm{B}}^{3} \cdot N_{\mathrm{NRC}},
$$

gives the maximum $\eta_{\text {int }}$ of the emission. Here, $\eta_{\text {int }}^{\max }$ is calculated under the assumption that every NRC within the exciton volume causes the nonradiative recombination. In Fig. 2, $\eta_{\text {int }}{ }^{\max }$ for GaN is shown as a function of $N_{\text {NRC }}$ (after Ref. 34). For comparison, the value of AlN is also shown. Here, $a_{\mathrm{B}}$ in GaN and AIN are 3.4 and $1.9 \mathrm{~nm}$, respectively. ${ }^{1}$ From this simple consideration, the commonly used assumption that $\eta_{\text {int }}$ is close to (but not absolutely) unity at 2 to

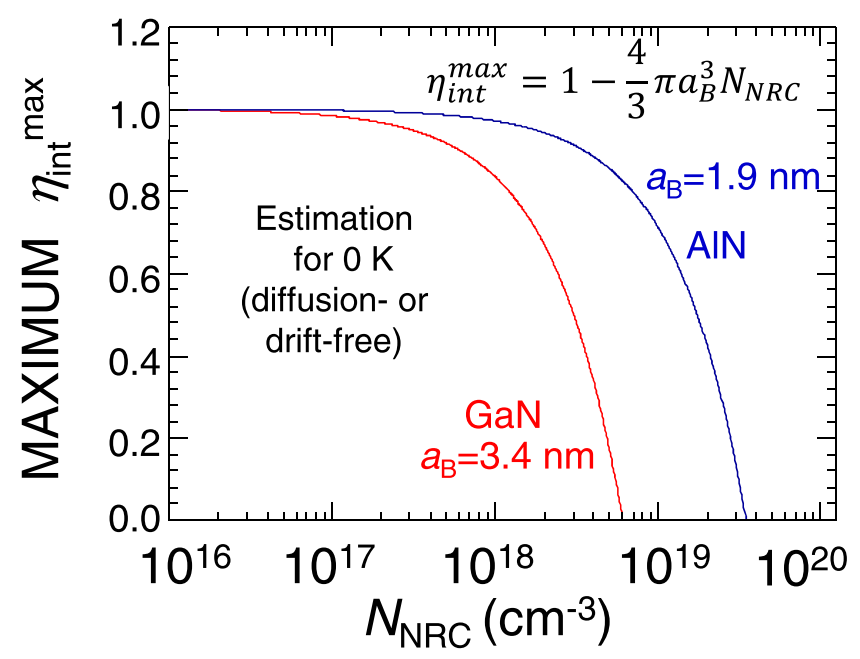

FIG. 2. Maximum $\eta_{\text {int }}\left(\eta_{\text {int }}^{\max }\right)$ at $0 \mathrm{~K}$ of a diffusion- or drift-free excitonic emission in GaN and AlN estimated as a function of NRC concentration, $N_{\mathrm{NRC}}$. The values are calculated under the assumption that every NRC exists within the exciton volume causes nonradiative recombination. [Modified with permission from Chichibu et al., Adv. Mater. 29, 1603644 (2017). Copyright 2017 John Wiley and Sons.] ${ }^{34}$ 
$4.2 \mathrm{~K}$ is not absolutely incorrect when $N_{\mathrm{NRC}}$ is lower than approximately a few times $10^{16} \mathrm{~cm}^{-3}$ for $\mathrm{GaN}$ and a few times $10^{17} \mathrm{~cm}^{-3}$ for AlN. ${ }^{34}$ We tentatively use these conditions and assumptions for discussing the high quality n-type HVPE FS-GaN samples. ${ }^{25-27}$

For probing the local carrier dynamics, the spatio-timeresolved cathodoluminescence (STRCL) measurement ${ }^{35-38}$ was carried out on several HVPE FS-GaN samples. ${ }^{25}$ By using STRCL, spatially resolved steady-state cathodoluminescence (SRCL) spectra and very local time-resolved cathodoluminescence (TRCL) signals can be obtained. A schematic drawing of our STRCL system will be found in Refs. 37 and 38. In this article, the data taken with the rearexcitation configuration ${ }^{35,36}$ photoelectron (PE)-gun are exclusively shown: by using a $300-\mathrm{mm}$ focal-length fused silica lens, approximately 200 fs pulses of a $3 \omega$ mode-locked $\mathrm{Al}_{2} \mathrm{O}_{3}$ :Ti laser were irradiated from the back side of a negatively biased, 15-nm-thick Au photocathode. The spot size on the photocathode is estimated to be $2.8 \times 10^{-5} \mathrm{~cm}^{2}$, giving rise to the maximum fluence of $35 \mu \mathrm{J} \cdot \mathrm{cm}^{-2}$ with an average power of $80 \mathrm{~mW}$ at $80 \mathrm{MHz}$ repetition rate. The PEs were extracted through an extractor electrode and focused to the filament position of the scanning electron microscope (SEM). The cathodoluminescence (CL) from the sample was collected using an off-axis parabolic mirror $(R=12 \mathrm{~mm})$ placed above the sample and analyzed using a grating spectrometer equipped with a CCD and a streak-camera with a temporal resolution of approximately $7 \mathrm{ps}$. Typical acceleration voltage $\left(V_{\text {acc }}\right)$ was $10 \mathrm{kV}$, and approximately 1.6 and 4 electrons per pulse were injected for TRCL and SRCL measurements, respectively. Using these conditions, approximately $5.6 \times 10^{16}$ and $1.4 \times 10^{17} \mathrm{~cm}^{-3} \mathrm{e}-\mathrm{h}$ pairs, respectively, would be generated. The former, at least, maintained the weak excitation conditions, in order to underline the nonradiative recombination process.

\section{Positron annihilation measurements}

A monoenergetic $\mathrm{e}^{+}$-beam line $\mathrm{e}^{11-13,21,30,34}$ was used to measure the Doppler broadening spectra of annihilating $\gamma$ ray radiation as a function of incident positron energy $E$ using a Ge detector. A spectrum with $3 \times 10^{6}$ counts was measured at each $E$. The low-momentum portion was characterized by the $S$ parameter, defined as the number of annihilation events for the energy range of $511 \mathrm{keV} \pm \Delta E_{\gamma}$, where $\Delta E_{\gamma}=0.76 \mathrm{keV}$, around the center of the peak, over the total counts. The $W$ parameter was calculated for the annihilation events in the tail of the spectra $(3.4 \mathrm{keV} \leq|\Delta E \gamma| \leq 6.8 \mathrm{keV})$ over the total counts. The relationship between $S$ and $E$ was analyzed by VEPFIT, a computer program developed by van Veen $e t a l .{ }^{24}$ The one-dimensional (1D) diffusion model of $\mathrm{e}^{+}$is expressed by ${ }^{8}$

$$
D_{+} \frac{d^{2}}{d z^{2}} n(z)-\kappa_{\mathrm{eff}}(z) n(z)+P(z, E)=0,
$$

where $D_{+}$is the diffusion coefficient of $\mathrm{e}^{+}, n(z)$ is the probability density of $\mathrm{e}^{+}$at a distance $z$ from the surface, $\kappa_{\text {eff }}(z)$ is the effective escape rate of $\mathrm{e}^{+}$from the diffusion process, and $P(z, E)$ is the implantation profile of $\mathrm{e}^{+}$. The diffusion length of positrons, $L_{+}(z)$, is given by

$$
L_{+}(z)=\sqrt{D_{+} / \kappa_{\mathrm{eff}}(z)}
$$

In the fitting procedure, a homogeneous distribution of defects was assumed. The $S-E$ curve was fitted to the following equation:

$$
S(E)=S_{e} F_{e}(E)+S_{S} F_{S}(E)+\sum S_{i} F_{i}(E)
$$

where $F e(E), F s(E)$, and $F i(E)$ are the fraction of epithermal (nonthermalized) positrons annihilated at the surface, that of positrons annihilated at the surface, and that of positrons annihilated in the $i$ th block, respectively $\left[F_{e}(E)+F_{s}(E)\right.$ $\left.+\Sigma F_{i}(E)=1\right]$. The values of $S_{\mathrm{e}}, S_{\mathrm{s}}$, and $S_{\mathrm{i}}$ are characteristic $S$ parameters for the respective annihilation events. The analytical procedures used in this study are similar to those described in Ref. 11. To examine the annihilation characteristics of positrons in detail, the coincidence detection system ${ }^{11}$ was also used. Spectra with about $5 \times 10^{6}$ counts were obtained and then characterized using the $S$ and $W$ parameters.

Doppler broadening spectra of the annihilating $\gamma$-rays were theoretically calculated using the QMAS (Quantum MAterials Simulator) code ${ }^{39,40}$ which uses valence-electron wavefunctions determined by the projector augmented-wave (PAW) method. ${ }^{41,42}$ To represent the exchange and correlation energies of electrons, the generalized gradient approximation was used. ${ }^{43}$ The calculations were carried out on orthorhombic supercells equivalent to $4 \times 4 \times 2$ wurtzite cells containing 128 atoms when there exist no vacancies. The supercell dimensions were $2 \sqrt{3} a_{0} \times 4 a_{0} \times 2 c_{0}$, where $a_{0}=0.3189 \mathrm{~nm}$ and $c_{0}=0.518625 \mathrm{~nm}$ were the lattice parameters of the wurtzite cell. For the supercell containing a defect, atomic positions in the fixed cell (with the experimental lattice parameters) were computationally optimized through a series of first-principles electronic-structure calculations. The formalism of the local density approximation ${ }^{44}$ was used in the calculation of the positron wave functions. The Doppler broadening spectra resulted from the annihilation of positrons in the delocalized (DF) state and the trapped states in cation vacancies were calculated. ${ }^{45}$ The simulated spectra were characterized by the $S$ and $W$ parameters. ${ }^{45}$

\section{RESULTS AND DISCUSSION}

\section{A. Origin of nonradiative recombination centers in n-type GaN}

In order to elucidate the species of native defects in UID and doped n-type GaN, $S-W$ relationship was studied. In Fig. 3, $(S, W)$ values of various n-type GaN samples are plotted by closed symbols. ${ }^{12,13}$ The sample ID names are shown in the figure. Because $(S, W)$ values for the HVPE FSGaN samples (C0, C1, C2, C3, C4, M1, and M2) almost coincided with that of MOVPE FS-GaN, their $(S, W)$ values are indicated by a single plot "FS-GaN in general." The $(S, W)$ values calculated ${ }^{45}$ for the annihilation of positrons at the delocalized state in the DF region, $\mathrm{V}_{\mathrm{Ga}}, \mathrm{V}_{\mathrm{N}}$, and $\mathrm{V}_{\mathrm{Ga}} \mathrm{V}_{\mathrm{N}}$ 


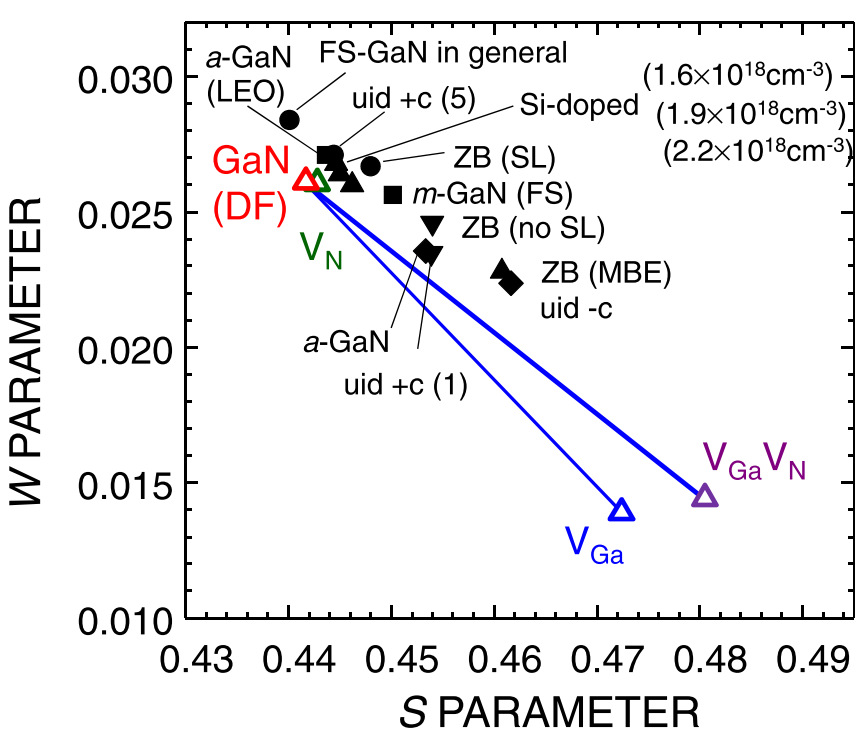

FIG. 3. $S$ - $W$ relationships for various UID and doped n-type GaN samples (closed symbols). The $(S, W)$ values calculated using the QMAS code for positron annihilation at the defect-free (DF) region (delocalized state), $\mathrm{V}_{\mathrm{Ga}}$, $\mathrm{V}_{\mathrm{N}}$, and $\mathrm{V}_{\mathrm{Ga}} \mathrm{V}_{\mathrm{N}}$ divacancy are shown by open triangles. ${ }^{45}$ The experimental data appear to align parallel to the line connecting $\left(S_{\mathrm{DF}}, W_{\mathrm{DF}}\right)$ and

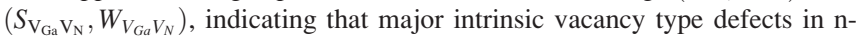
type $\mathrm{GaN}$ are $\mathrm{V}_{\mathrm{Ga}} \mathrm{V}_{\mathrm{N}}$ divacancies. [Experimental data plots are reproduced with permission from Appl. Phys. Lett. 86, 021914 (2005). Copyright 2005 AIP Publishing LLC. $]^{12}$

divacancy are shown by open triangles. In the $S-W$ plot, when the sample contains single-species of vacancy-type defects, positrons annihilate from DF state or the trapped state due to the defects. In this case, $(S, W)$ becomes a weighted average of the characteristic $(S, W)$ values for DF and trapped states, namely $\left(S_{\mathrm{DF}}, W_{\mathrm{DF}}\right)$ and $\left(S_{\text {defect }}, W_{\text {defect }}\right)$, respectively, and it should lie on a line connecting those two values. Here we mention that the dynamic range of PAS measurement for $\mathrm{V}_{\mathrm{Ga}}$ in $\mathrm{GaN}$ is approximately between $10^{16}$ and $10^{19} \mathrm{~cm}^{-3}$, at which positrons implanted in the sample are nearly fully delocalized in DF regions and fully trapped by $\mathrm{V}_{\mathrm{Ga}} \mathrm{s}$, respectively. Accordingly, $\left[\mathrm{V}_{\mathrm{Ga}}\right]$ is lower than $10^{15} \mathrm{~cm}^{-3}$ for $\left(S_{\mathrm{DF}}, W_{\mathrm{DF}}\right)$ and higher than $10^{19} \mathrm{~cm}^{-3}$ for $\left(S_{V_{G a}}, W_{V_{G a}}\right)$. In Fig. 3, the experimental data appear to align parallel to the line connecting $\left(S_{\mathrm{DF}}, W_{\mathrm{DF}}\right)$ and $\left(S_{V_{G a} V_{N}}, W_{V_{G a} V_{N}}\right){ }^{45}$ More precisely, the measured $(S, W)$ for FS-GaN lie to the higher left of the calculated $(S, W)$ for DF-GaN. This difference could be due to several causes such as the limitations of first-principles calculations applied to Doppler broadening spectra, the experimental background, and/or the energy resolutions of our Ge detectors. Because FS-GaN in general showed the smallest $S$ (and largest $W$ ), vacancy concentrations in them are close to or lower than the detection limit of PAS measurement being lower than $10^{16} \mathrm{~cm}^{-3}$. ${ }^{45}$ From these results, the major intrinsic vacancy type defects in n-type $\mathrm{GaN}$ is identified as $\mathrm{V}_{\mathrm{Ga}} \mathrm{V}_{\mathrm{N}}$ divacancies, and $\left[\mathrm{V}_{\mathrm{Ga}} \mathrm{V}_{\mathrm{N}}\right]$ of the samples shown in Fig. 3 are in the range between lower than $10^{16} \mathrm{~cm}^{-3}$ to approximately $5 \times 10^{17} \mathrm{~cm}^{-3}$.

The $\tau_{1}$ values of the NBE emission in these n-type GaN at $293 \mathrm{~K}$ are plotted as functions of $S$ and $L_{+}$in Figs. 4(a) and $4(\mathrm{~b})$, respectively. The data for the variety of samples ${ }^{12}$

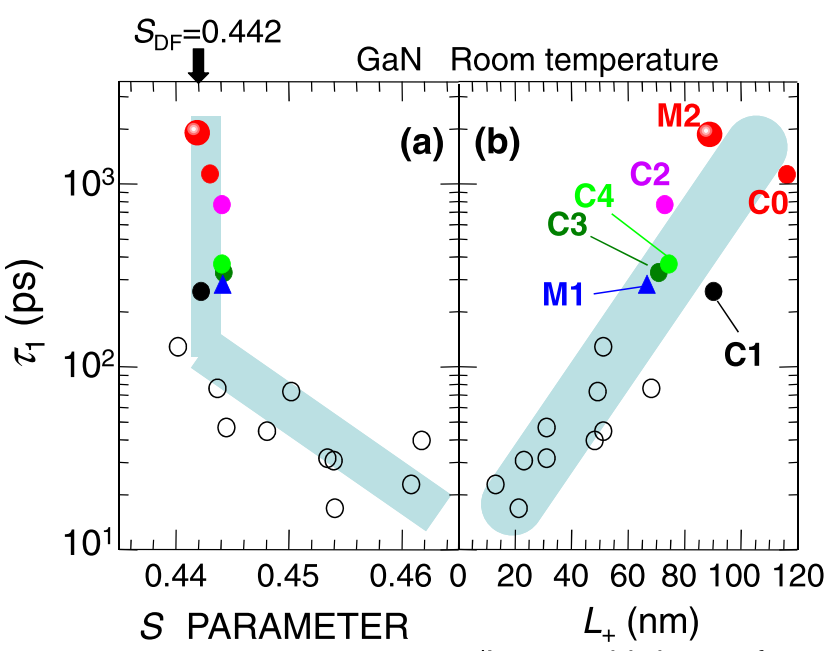

(Size or concentration of $\mathrm{V}_{\mathrm{Ga}}$ ) $\begin{gathered}\text { (Inverse third root of gross } \\ \text { point defect concentration) }\end{gathered}$

FIG. 4. Fast component of the TRPL decay curve $\left(\tau_{1}\right)$ for the NBE emission of GaN samples at room temperature as functions of (a) Doppler broadening $S$ parameter and (b) positron diffusion length $L_{+}$. The $\tau_{1}$ values for a variety of GaN samples including Ga-polar and N-polar c-plane, $a$ - and $m$-plane nonpolar, and zinc blende thin films and bulk crystals with high and low TDDs and high and low electron concentrations $(n)$ are represented by open circles ${ }^{12}$ and those of HVPE FS-GaN ${ }^{13,25-27,29}$ are represented by closed symbols. Characteristic $S$ for DF-GaN $\left(S_{\mathrm{DF}}=0.442\right)$ (Ref. 45) is shown by the arrow on the upper horizontal axis in (a). [Reproduced with permission from $\mathrm{J}$. Appl. Phys. 111, 103518 (2012). Copyright 2012 AIP Publishing LLC]. ${ }^{13}$

with high and low electron concentrations (n) shown in Fig. 3 are represented by open circles and those for HVPE FS-GaN ${ }^{13,25-27,29}$ are represented by closed symbols. Characteristic $S$ for DF-GaN ( $\left.S_{\mathrm{DF}}=0.442\right)$ (Ref. 40) is shown by the arrow on the upper horizontal axis in Fig. 4(a). Obviously, $\tau_{1}$ increases with decreasing $S$. Because $S$ of FS-GaN samples has already reached $S_{\mathrm{DF}}, \tau_{1}$ distributes from $0.1 \mathrm{~ns}$ to $1.1 \mathrm{~ns}$ for the same $S\left(=S_{\mathrm{DF}}\right)$, as shown by the vertical guide to the eye. On the other hand, $\tau_{1}$ increases with the increase in $L_{+}$, and eventually reaches $1.1 \mathrm{~ns}$ for $L_{+}$ $=116 \mathrm{~nm}$ of the sample C $0 .{ }^{13}$ Here we note that $N_{\mathrm{NRC}}$ calculated under the assumption that $L_{+}$corresponds to an inverse third root of $N_{\mathrm{NRC}}$ are $10^{15} \mathrm{~cm}^{-3} \mathrm{~nm}$ for $L_{+}=100 \mathrm{~nm}$, $10^{16} \mathrm{~cm}^{-3} \mathrm{~nm}$ for $L_{+}=46 \mathrm{~nm}, 10^{17} \mathrm{~cm}^{-3} \mathrm{~nm}$ for $L_{+}=22 \mathrm{~nm}$, and $10^{18} \mathrm{~cm}^{-3} \mathrm{~nm}$ for $L_{+}=10 \mathrm{~nm}$. The sample M2, which was grown ${ }^{27}$ by HVPE on a SCAAT seed, ${ }^{28}$ exhibited the longest $\tau_{1}$ value. $^{29}$ These results confirm that principal limiting factor of $\tau_{\mathrm{NR}}$ and thereby $\eta_{\text {int }}$ at room temperature is gross concentration of point defects (and defect complexes), which are incorporated with $\mathrm{V}_{\mathrm{Ga}}$. From the results shown in Figs. 3 and 4, defect complexes containing $\mathrm{V}_{\mathrm{Ga}},{ }^{12,13}$ more precisely $\mathrm{V}_{\mathrm{Ga}} \mathrm{V}_{\mathrm{N}}$ divacancies, are identified as the major intrinsic NRCs in n-type GaN.

Spectrally integrated TRPL signals and the quenching ratio $\left(R_{\mathrm{q}}\right)$, which is defined as the integrated spectral intensity of whole NBE PL at a given $T$ divided by that at $7-10 \mathrm{~K}$ $\left[I_{\mathrm{PL}}(T \mathrm{~K}) / I_{\mathrm{PL}}(7 \mathrm{~K})\right]$ under the weak excitation regime, ${ }^{4,12,13}$ of sample $\mathrm{C} 0$ are shown as a function of $T$ in Figs. 5(a) and 5 (b), respectively. ${ }^{13}$ In this particular sample, substitution of $R_{\mathrm{q}}$ as $\eta_{\text {int }}^{e q .}$ is reasonable, as $N_{\mathrm{NRC}}\left(<10^{16} \mathrm{~cm}^{-3}\right)$ is far lower than the critical value given in Fig. 2. Evidence to support this is that $R_{\mathrm{q}}$ at $300 \mathrm{~K}$ [2.3\% in Fig. 5(b)] almost agrees with 

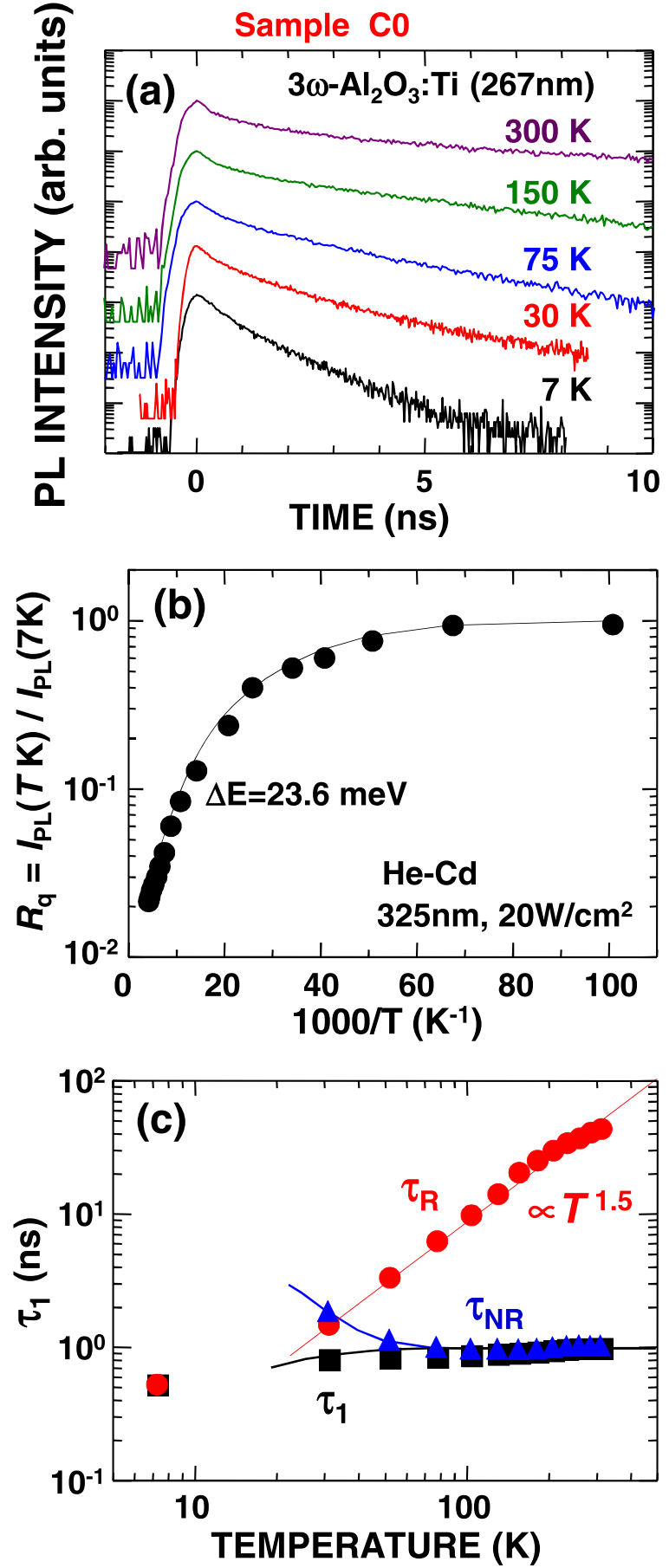

FIG. 5. (a) Spectrally integrated TRPL decay signals measured for whole NBE emissions of the $c$-plane FS-GaN $(\mathrm{C} 0)$ as a function of $T$. (b) Spectrally integrated whole NBE PL intensity at a given $T$ divided by that at $7 \mathrm{~K}$ [quenching ratio $\left.R_{\mathrm{q}}=I_{\mathrm{PL}}(T \mathrm{~K}) / I_{\mathrm{PL}}(7 \mathrm{~K})\right]$ as a function of $1 / T$. At $300 \mathrm{~K}, R_{\mathrm{q}}$ is $2.3 \%$. (c) Temperature dependencies of $\tau_{1}, \tau_{\mathrm{R}}$, and $\tau_{\mathrm{NR}}$. The values of $\tau_{\mathrm{R}}$ and $\tau_{\mathrm{NR}}$ are derived from $\tau_{1}$ and $R_{\mathrm{q}}$ using Eqs. (1) and (3), where $\tau_{1}$ and $R_{\mathrm{q}}$ are substituted for $\tau_{\mathrm{PL}}$ and $\eta_{\mathrm{int}}$, respectively. [Reproduced with permission from J. Appl. Phys. 111, 103518 (2012). Copyright 2012 AIP Publishing LLC]. ${ }^{13}$

the value obtained using the omnidirectional photoluminescence (ODPL) spectroscopy, ${ }^{46}$ by which absolute $\eta_{\text {int }}$ can be obtained from absolute external quantum efficiency $\left(\eta_{\text {ext }}\right)$ being $2 \%$ to $3 \%$ at the same excitation power density of $20 \mathrm{~W} \cdot \mathrm{cm}^{-2}$ at $300 \mathrm{~K}$. We note that this assumption fails when using high-excitation conditions like very initial excitation stage of TRPL/TRCL measurements. The TRPL signal showed nearly double-exponential decay shape, and the decay curve became modest with increasing $T$. The appearance of two (or three) decay components most probably reflects the fact that several portions of different $N_{\mathrm{NRC}}$, which are away beyond the diffusion length of minority carriers $\left(L_{\text {minority }}\right)$, are simultaneously observed in our macroarea measurements with 1-mm-diameter spot size, where $L_{\text {minority }}=\sqrt{D \cdot \tau}$ and $D$ and $\tau$ are their diffusivity and lifetime, respectively. This issue will be discussed later with the results of STRCL measurement.

The $\tau_{1}$ value slightly increased with $T$ up to $100 \mathrm{~K}$ and leveled off at approximately $1.1 \mathrm{~ns}$ above $150 \mathrm{~K}$, as plotted by squares in Fig. 5(c). For considering the temperature dependency of recombination dynamics, $\tau_{\mathrm{R}}$ and $\tau_{\mathrm{NR}}$ are deduced from the measured $\tau_{1}$ and $R_{\mathrm{q}}$ using Eqs. (1) and (3), where $\tau_{1}$ and $R_{\mathrm{q}}$ are substituted for $\tau_{\mathrm{PL}}$ and $\eta_{\text {int }}$, respectively. The results are plotted in Fig. 5(c) by circles and triangles, respectively, for $\tau_{\mathrm{R}}$ and $\tau_{\mathrm{NR}}$. As $\eta_{\text {int }}$ decreases to $0.5, \tau_{\mathrm{R}}$ and $\tau_{\mathrm{NR}}$ crossover at around $40 \mathrm{~K}$. Below (above) this temperature, $\tau_{1}$ is dominated by $\tau_{\mathrm{R}}\left(\tau_{\mathrm{NR}}\right)$. As shown, $\tau_{\mathrm{NR}}$ lies on an asymptote with temperature rise, and the room temperature value is $1.1 \mathrm{~ns}$. The longest $\tau_{\mathrm{NR}}$ value among the samples measured under the same excitation conditions was $2.07 \mathrm{~ns}$ for M2. ${ }^{29}$ A saturation of the decrease in $\tau_{\mathrm{NR}}$ indicates that NRCs are fully activated, reflecting low gross $N_{\text {NRC }}$. The decrease in $\eta_{\text {int }}$ at elevated temperatures is, therefore, due to the increase in $\tau_{\mathrm{R}}$. As a result, $\eta_{\text {int }}$ is estimated to be $2.3 \%$ at $300 \mathrm{~K}$. As stated above, this value nearly agrees with the $\eta_{\text {int }}$ value obtained by the ODPL measurement. ${ }^{46}$ It should be noted that $\tau_{\mathrm{R}}$ increases according to $T^{1.5}$, which is characteristics of particles in $3 \mathrm{D}$ space. ${ }^{47,48}$ The $\tau_{\mathrm{R}}$ value is extrapolated to $130 \mathrm{ps}$ at $7 \mathrm{~K}$ and $40-50 \mathrm{~ns}$ at $300 \mathrm{~K}$. The latter value is consistent with $\tau_{\mathrm{R}}$ value for the NBE PL peak in low TDD FS-GaN at $300 \mathrm{~K}$ reported recently using simultaneous photoluminescence and photo-acoustic measurements ${ }^{49}$ being $50 \mathrm{~ns}$. These experimental facts that two independent measurements ${ }^{13,49}$ showed the same $\tau_{\mathrm{R}}$ at $300 \mathrm{~K}$ being $40-50 \mathrm{~ns}$ and other two independent measurements ${ }^{13,46}$ showed the same $\eta_{\text {int }}$ at $300 \mathrm{~K}$ being $2 \%-3 \%$ at the same excitation power densities support the accuracy of the analysis carried out herein.

In order to visualize spatial variations of $\eta_{\text {int }}$ and $\tau_{\mathrm{NR}}$ for the NBE emission, STRCL measurement was conducted near the region surrounded by the inversion domain boundaries (IDBs) in the HVPE FS-GaN sample C3. We note that IDBs are occasionally formed by some growth perturbations. Figures 6(a)-6(c), respectively, illustrate SEM image and CL intensity $\left(I_{\mathrm{CL}}\right)$ images recorded for the NBE emission at $293 \mathrm{~K}$ and $20 \mathrm{~K} .{ }^{37}$ These CL images were taken with a probe current of $100 \mathrm{pA}$ and a dwell time of $200 \mathrm{~ms}$, corresponding to 30 min per image. The SEM image showed a trapezoidal dimple surrounded by the IDBs. Also, several dark spots were found although their contrasts were rather faint. These spots were also observed as the dark spots in the CL image at $293 \mathrm{~K}$, as shown in Fig. 6(b). The CL image at $293 \mathrm{~K}$ showed complex structures since its contrast reflects spatial distribution of NRCs, while its spatial resolution is limited by $L_{\text {minority. }}$ The sharpness of the CL image taken at $20 \mathrm{~K}$ was greatly improved because $D$ approaches zero towards 


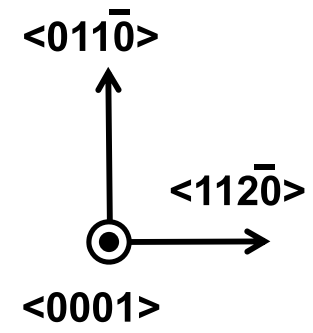

(b) NBE CL (293K)

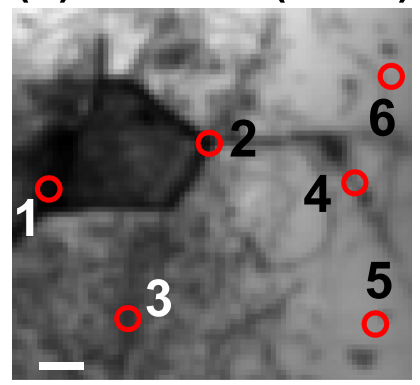

$10 \mu \mathrm{m}$ (a) SEM (293K)
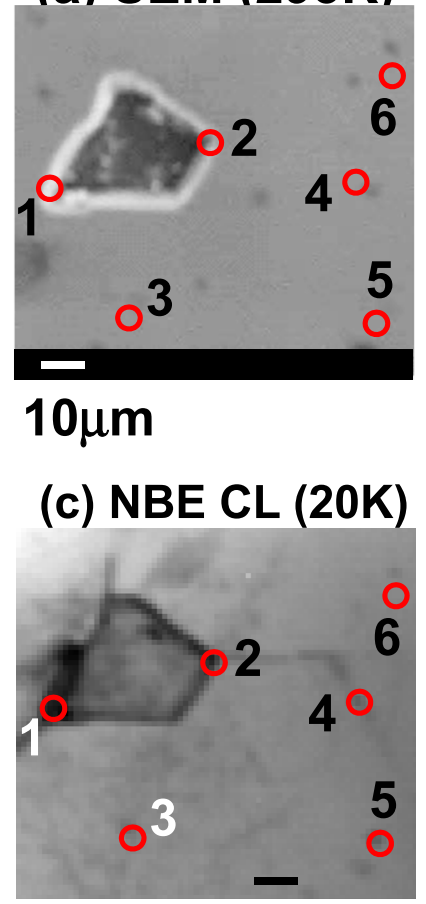

$10 \mu \mathrm{m}$

FIG. 6. (a) SEM image, (b) NBE CL intensity image taken at $293 \mathrm{~K}$, and (c) NBE CL intensity image taken at $20 \mathrm{~K}$ for the FS-GaN sample C3. [Reproduced with permission from Appl. Phys. Lett. 101, 212106 (2012). Copyright 2012 AIP Publishing LLC]. ${ }^{37}$

$0 \mathrm{~K}$ according to Einstein's relation $D=\mu \frac{k_{\mathrm{B}} T}{q}$, where $k_{\mathrm{B}}$ is the Boltzmann constant, $q$ the electric charge, and $\mu$ the mobility. Therefore, the dark areas and lines that remain in Fig. 6(c) are possibly due to the clusters of NRCs and/or the absence of the material itself. In both Figs. 6(b) and 6(c), it can be seen that some straight line structures run from the corners of the trapezoid parallel to $m$-planes. This implies that the tensile stress accumulated around the IDBs is relaxed by introducing cracks. ${ }^{37}$ Since there are no corresponding structures in the SEM image, it is likely that these cracks are atomically thin and run under the surface, and which can specifically be detected in the CL images due to the finite implantation depth of the $e$-beam and the longitudinal diffusion of the minority carriers.

The virtue of STRCL is that it is readily accessible to the local recombination dynamics for a particular emission peak. Local time-integrated cathodoluminescence (TICL) and TRCL decay signals for the NBE emission of C3 measured at room temperature at the positions 1 to 6 encircled in Fig. 6 are shown in Figs. 7(a) and 7(b), respectively. ${ }^{37}$ In this instance, the probe current was decreased to $25 \mathrm{pA}$, which amounts to 1.6 electrons per pulse, in order to prevent any degradation in temporal resolution. ${ }^{37}$ The resultant number of excited electron-hole pairs in $\mathrm{GaN}$ is deduced to be less than 2000 from the empirical relation given in Ref. 50. We note that this excitation power density gives the $\tau_{1}$ value for the TRPL decay constant of a GaN template when excited with the laser fluence of $2 \mu \mathrm{J} \cdot \mathrm{cm}^{-2}$ (Ref. 51). This value is an order of magnitude higher than that used for the TRPL

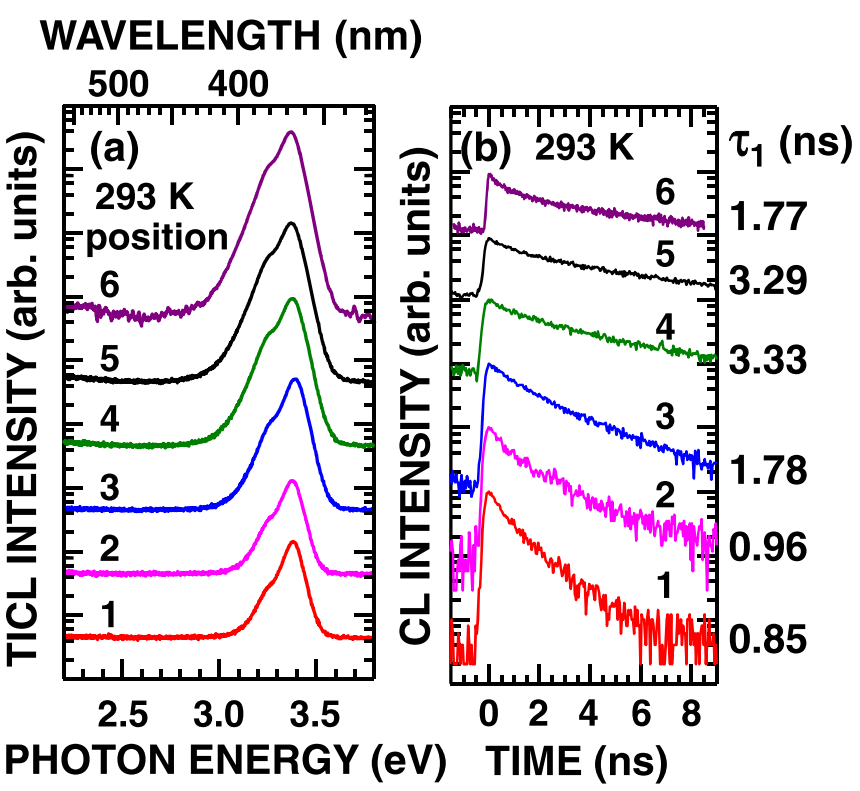

FIG. 7. Position dependent (a) TICL spectra and (b) TRCL decay signals for the NBE emission of FS-GaN sample C3 measured at $293 \mathrm{~K}$. The number corresponds to the position encircled in Fig. 6. [Reproduced with permission from Appl. Phys. Lett. 101, 212106 (2012). Copyright 2012 AIP Publishing LLC]. ${ }^{37}$

measurement. However, weak excitation conditions are still maintained. In these local CL spectra in Fig. 7(a), subtle redshifts of the NBE emission peak inside and on the peripheries of the trapezoid were found. This can be attributed to the local strain or increased residual electron concentration. Although we fitted the TRCL decay curves in Fig. 7(b) by a double exponential function, the curves at several positions can be mostly fitted by a single exponential function, different from the macroarea TRPL decay curve at room temperature shown in Fig. 5(a). This result may indicate that local excitation by a focused e-beam gives rise to the excitation of a portion of nearly homogeneous $N_{\mathrm{NRC}}$ within $L_{\text {minority. As }}$ shown, $\tau_{1}$ significantly varied depending on the positions. The decrease of $\tau_{1}$ near the visual defects in the CL image at 293 K [see Fig. 7(b)] can be understood as enhanced recombination at NRCs because $\tau_{1}$ at room temperature is dominated by $\tau_{\mathrm{NR}}$, as shown in Fig. 5(c). By contrast, local $\tau_{1}$ values measured at $10 \mathrm{~K}$ were almost independent of the positions being 180 ps (data not shown here). This is reasonable since $\tau_{\mathrm{R}}$ dominates the CL lifetime $\left(\tau_{\mathrm{CL}}\right)$ at low temperature.

The values of local $R_{\mathrm{q}}\left[I_{\mathrm{CL}}(T \mathrm{~K}) / I_{\mathrm{CL}}(20 \mathrm{~K})\right]$ for the NBE CL of HVPE FS-GaN (C3 and C4) are plotted as a function of $\tau_{1}$ in Fig. 8. For the sample C3, $R_{\mathrm{q}}$ values measured at the positions $1-6$ are used. The $R_{\mathrm{q}}$ value can be used as $\eta_{\text {int }}$ since $N_{\text {NRC }}$ in FS-GaN is lower than the critical value shown in Fig. 2 and STRCL was carried out under the weak excitation conditions. $^{37}$ The macroarea PL data for $\mathrm{C} 0, \mathrm{M} 2$, and $\mathrm{GaN}$ templates are also shown. As can be seen, $\eta_{\text {int }}$ appears to linearly increase with the increasing $\tau_{1}$. This result is reasonable according to Eq. (3), when we assume that $\tau_{\mathrm{R}}$ of $\mathrm{GaN}$ is $40 \mathrm{~ns}$ (Ref. 13) and $\tau_{\mathrm{CL}}$ is dominated by $\tau_{\mathrm{NR}}$ at room temperature. Although the overall trend of higher $\eta_{\text {int }}$ in the local measurement may indicate somewhat higher excitation 


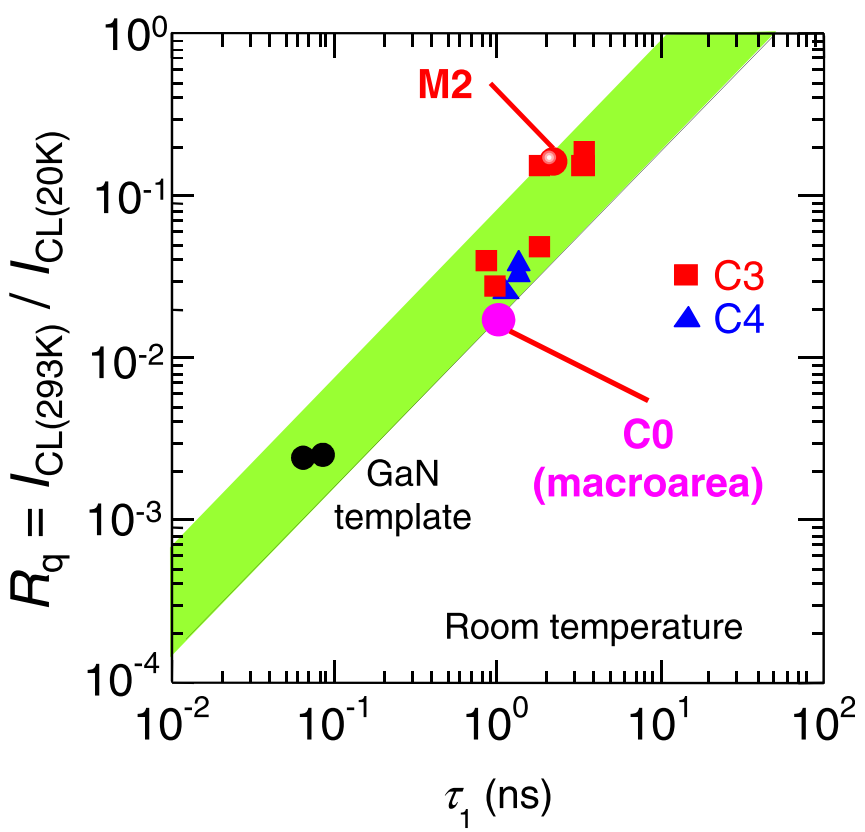

FIG. 8. Spatially resolved local $R_{\mathrm{q}}$ at room temperature $\left[I_{\mathrm{CL}}(293 \mathrm{~K}) /\right.$ $\left.I_{\mathrm{CL}}(20 \mathrm{~K})\right]$ for the NBE emission of HVPE FS-GaN samples $\mathrm{C} 3$ and $\mathrm{C} 4,{ }^{37}$ as a function of $\tau_{1}$. The macroarea PL data for $\mathrm{C} 0, \mathrm{M} 2$, and $\mathrm{GaN}$ templates are also shown. [Reproduced with permission from Appl. Phys. Lett. 101, 212106 (2012). Copyright 2012 AIP Publishing LLC]. ${ }^{37}$

density used, ${ }^{38}$ the spatially focused excitation in STRCL can selectively probe highly luminescent regions that are less affected by NRCs. As a result, a record high $\eta_{\text {int }}$ of about $20 \%$ was obtained for position 4 in Fig. 2, where $\tau_{1}$ was about $3.33 \mathrm{~ns}^{37}$

For understanding the role of NRCs on the recombination dynamics, $\tau_{\mathrm{PL}}$ of HVPE FS-GaN (C0) and MOVPE FS$\mathrm{GaN}$ at $300 \mathrm{~K}$ is plotted as a function of $N_{\mathrm{NRC}}$ in Fig. 9 by closed circles. ${ }^{34}$ Here, $\left[\mathrm{V}_{\mathrm{Ga}} \mathrm{V}_{\mathrm{N}}\right.$ ] estimated from Figs. 3 and 4 are used as $N_{\text {NRC. }}$ Right $y$-axis shows $\eta_{\text {int }}$ at $300 \mathrm{~K}$ derived from Eqs. (1) and (3) using the intrinsic $\tau_{\mathrm{R}}$ of $40 \mathrm{~ns} .^{13,37,49}$

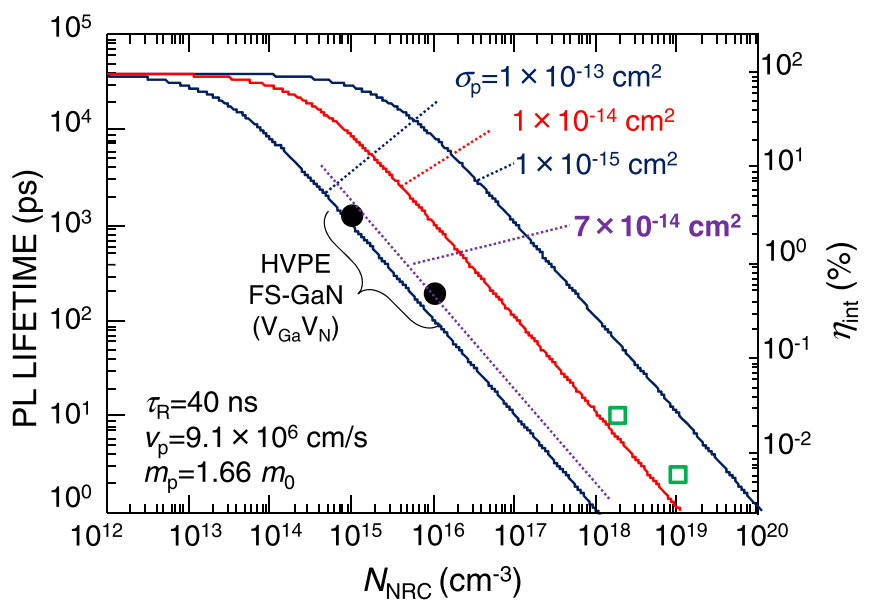

FIG. 9. PL lifetime $\left(\tau_{\mathrm{PL}}\right)$ and corresponding $\eta_{\text {int }}$ at $300 \mathrm{~K}$ of HVPE FS-GaN (C0) and MOVPE FS-GaN as a function of $N_{\mathrm{NRC}}$, which is $\left[\mathrm{V}_{\mathrm{Ga}} \mathrm{V}_{\mathrm{N}}\right]$ (closed circles). The $\tau_{\mathrm{PL}}$ data for Fe-doped $\mathrm{GaN}^{52}$ are also shown by open squares for comparison. Three $\tau_{\mathrm{PL}}-N_{\mathrm{NRC}}$ curves are drawn for the cases with $\sigma_{\mathrm{p}}$ ranging from $1 \times 10^{-15}$ to $1 \times 10^{-13} \mathrm{~cm}^{2}$. [Reproduced with permission from Chichibu et al., Adv. Mater. 29, 1603644 (2017). Copyright 2017 John Wiley and Sons]. ${ }^{34}$
The $\tau_{\mathrm{PL}}$ values reported by Aggerstam et al. ${ }^{52}$ for Fe-doped $\mathrm{GaN}$ are shown by open squares for comparison, as $\mathrm{Fe}_{\mathrm{Ga}}{ }^{2+/ 3+}$ deep acceptors act as killer NRCs. Obviously, $\tau_{\mathrm{PL}}$ is decreased by increasing $N_{\mathrm{NRC}}$. In n-type $\mathrm{GaN}, \tau_{\mathrm{NR}}$ is limited by $C_{\mathrm{p}}$, which is a product of $\sigma_{\mathrm{p}}$ and $v_{\mathrm{p}}\left(C_{\mathrm{p}}=\sigma_{\mathrm{p}} \cdot v_{\mathrm{p}}\right)$, and $N_{\mathrm{NRC}}$. Then, $\tau_{\mathrm{PL}}-N_{\mathrm{NRC}}$ relationship can be predicted using the relation $1 / \tau_{\mathrm{PL}}=1 / \tau_{\mathrm{R}}+v_{\mathrm{p}} \cdot \sigma_{\mathrm{p}} \cdot N_{\mathrm{NRC}}$. This relationship predicts that $\tau_{\mathrm{PL}}-N_{\mathrm{NRC}}$ relation shows a straight line under low excitation and high $N_{\mathrm{NRC}}$ conditions, where $\tau_{\mathrm{NR}}$ dominates $\tau_{\mathrm{PL}}$. In Fig. 9, three ideal curves are drawn for representative $\sigma_{\mathrm{p}}$ of $1 \times 10^{-15}, 1 \times 10^{-14}$, and $1 \times 10^{-13} \mathrm{~cm}^{2}$ using $\tau_{\mathrm{R}}$ $=40 \mathrm{~ns}$ and $m_{\mathrm{p}}=1.66 m_{0}$, where $m_{0}$ is a free electron mass. As shown, $\sigma_{\mathrm{p}}$ of the intrinsic NRCs in $\mathrm{GaN}\left(\mathrm{V}_{\mathrm{Ga}} \mathrm{V}_{\mathrm{N}}\right)$ is obtained as approximately $7 \times 10^{-14} \mathrm{~cm}^{2}$. It seems that $\mathrm{V}_{\mathrm{Ga}} \mathrm{V}_{\mathrm{N}}$ has larger $\sigma_{\mathrm{p}}$ than isolated $\mathrm{Fe}_{\mathrm{Ga}}{ }^{2+/ 3+}$ center ${ }^{52}$ as it is a complex defect. The present $\sigma_{\mathrm{p}}$ value is close to those previously reported for a carbon deep acceptor on a $\mathrm{N}$ site $\left(\mathrm{C}_{\mathrm{N}}\right)^{16}$ or another acceptor-type defects in GaN (Refs. 53 and 54), as well as those of the $Z_{1 / 2}$ center $^{55}$ in $4 \mathrm{H}$-SiC being $6.5 \times 10^{-14}$ $\mathrm{cm}^{2}$ (Ref. 56), of which origin is a $\mathrm{C}$ vacancy, $\mathrm{V}_{\mathrm{C}}{ }^{57}$

\section{B. Influences of $\mathbf{N}$ vacancies in Mg-doped GaN}

Different from the case of n-type $\mathrm{GaN}, \mathrm{V}_{\mathrm{N}}$ formation $^{15,20,58}$ influences the optical properties of epitaxial and $\mathrm{I} / \mathrm{I} \mathrm{GaN}$ :Mg. In this section, low temperature and room temperature PL features of those samples are discussed in order. The PL spectra at $10 \mathrm{~K}$ of the UID and epitaxial GaN:Mg films fabricated on a HVPE FS-GaN substrate after annealing at $1300{ }^{\circ} \mathrm{C}$ are shown in Figs. 10 (a)-10(d) by upper solid lines. $^{32}$ The PL intensity axis has a unit of count per second (cps); hence, the absolute intensities can be compared. As shown in Fig. 10(a), the UID GaN film exhibited distinct NBE PL peaks and shoulders originating from the recombination of free excitons (FXs), recombination of excitons bound to a neutral donor (DBEs), and their LO phonon replicas at the energies higher than $3.2 \mathrm{eV}$. In addition to these, YL band ${ }^{14-16}$ was also found. It may have two independent origins, namely, the transition of an electron in the conduction band $(\mathrm{CB})$ or bound to a donor to $\mathrm{C}_{\mathrm{N}}$ deep acceptor ${ }^{56}$ and a donor-acceptor-pair (DAP) recombination between a donor impurity such as an oxygen on a $\mathrm{N}$ site and a $\mathrm{V}_{\mathrm{Ga}} \cdot{ }^{15}$ The dominant excitonic emission peak switched from DBE in UID GaN to the peak originating from the recombination of excitons bound to a neutral $\mathrm{Mg}_{\mathrm{Ga}}$ acceptor (ABE) in the epitaxial GaN:Mg with $[\mathrm{Mg}]$ of $5 \times 10^{17}$ and $2 \times 10^{18} \mathrm{~cm}^{-3}$, as shown in Figs. 10(b) and 10(c), respectively. In addition, a UV luminescence (UVL) band originating from a transition of an electron in $\mathrm{CB}$ or bound to a shallow donor to a $\mathrm{Mg}_{\mathrm{Ga}}$ acceptor at around $3.26 \mathrm{eV}$ (Ref. 58) appeared in the PL spectra of epitaxial GaN:Mg films [Figs. 10(b)-10(d)]. Such a simultaneous observation of $\mathrm{ABE}$ and UVL indicates the formation of $\mathrm{Mg}_{\mathrm{Ga}}$ acceptors. Their PL spectra also exhibited characteristic emission bands originating from deep levels (DLs) at around 2.35 and $1.80 \mathrm{eV}$, instead of YL. They are generally known as the green luminescence (GL) band and red luminescence (RL) band, respectively. ${ }^{58}$ Accordingly, the emergence of GL and RL is also attributable to one of the basic Mg-doping effects in GaN. By using the first- 


\section{undoped / [Mg]: $10^{17} \mathrm{~cm}^{-3} \quad 10^{18} \mathrm{~cm}^{-3} \quad 10^{19} \mathrm{~cm}^{-3}$}
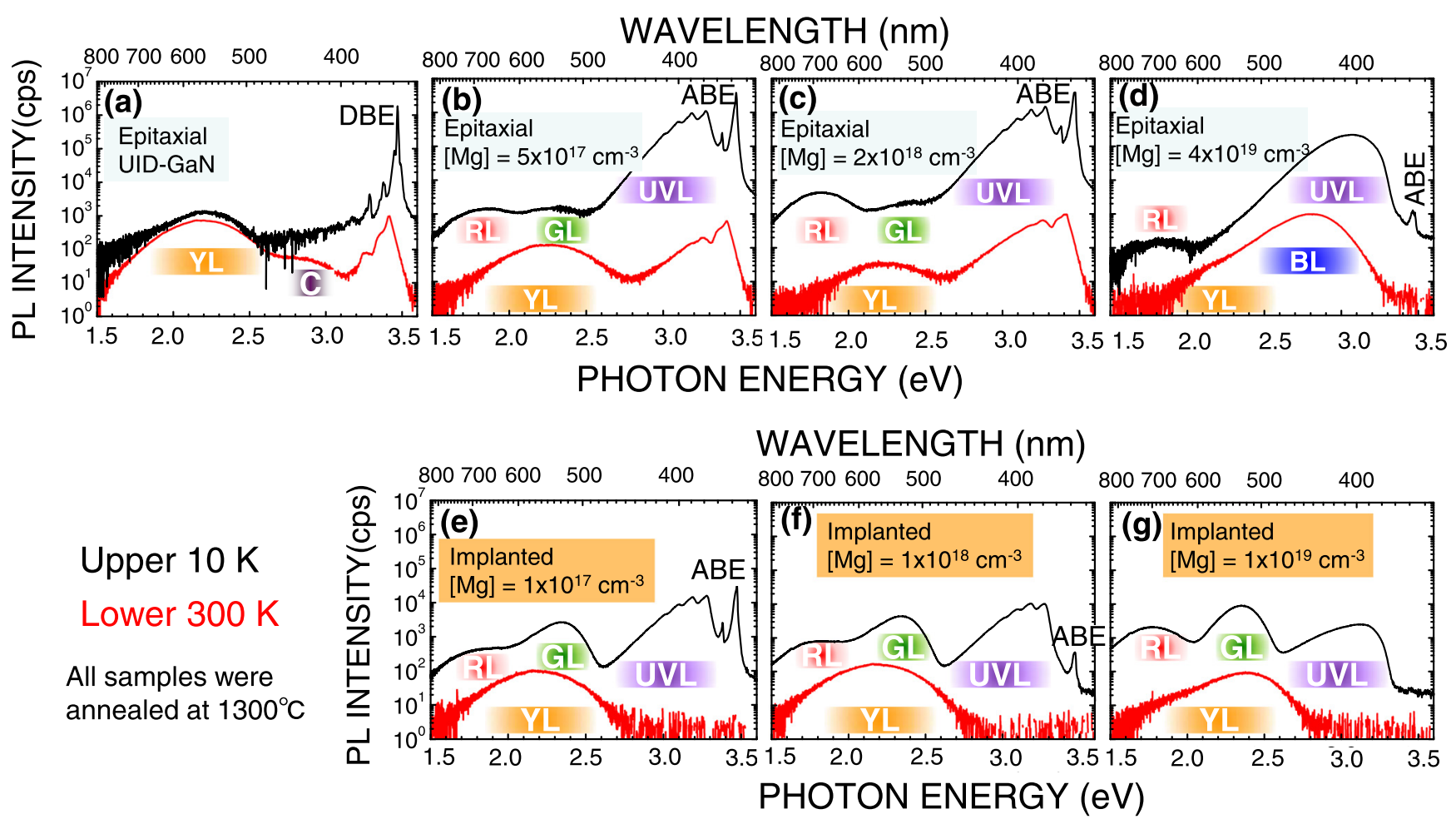

FIG. 10. Steady-state PL spectra of (a) UID GaN, (b)-(d) epitaxial GaN:Mg, and (e)-(g) I/I GaN:Mg films grown on HVPE FS-GaN substrates. The [Mg] values for the epitaxial GaN:Mg were (b) $5 \times 10^{17}$, (c) $2 \times 10^{18}$, and (d) $4 \times 10^{19} \mathrm{~cm}^{-3}$. The $[\mathrm{Mg}]$ values for the flat concentration region (nearly $500 \mathrm{~nm}$ from the surface) of I/I GaN:Mg were (e) $1 \times 10^{17}$, (f) $1 \times 10^{18}$, and $(\mathrm{g}) 1 \times 10^{19} \mathrm{~cm}^{-3}$. The PL measurement was carried out at $10 \mathrm{~K}$ (top traces) and $300 \mathrm{~K}$ (bottom traces). [Reproduced with permission from Kojima et al., Appl. Phys. Express 10, 061002 (2017). Copyright 2017 The Japan Society of Applied Physics]. ${ }^{32}$

principles calculations, Reshchikov et al. ${ }^{58}$ have suggested that $\mathrm{V}_{\mathrm{N}}$ is the origin of GL, because UID GaN epitaxial films grown by MBE under Ga-rich conditions frequently exhibit GL without Mg-doping at $300 \mathrm{~K}$, where such UID films were highly resistive. The enhanced formation of $\mathrm{V}_{\mathrm{N}}$ in $\mathrm{GaN}: \mathrm{Mg}$ films is likely as $E_{\mathrm{Form}}$ of $\mathrm{V}_{\mathrm{N}}$ and $\mathrm{V}_{\mathrm{N}}-\mathrm{Mg}_{\mathrm{Ga}}$ complexes decrease with lowering $E_{\mathrm{F}} \cdot{ }^{20,58}$ In GaN:Mg film with $[\mathrm{Mg}]$ of $4 \times 10^{19} \mathrm{~cm}^{-3}$, integrated spectral NBE emission intensity was lower than that of UID and less Mg-doped samples, as shown in Fig. 10(d). In such heavily Mg-doped GaN epilayers, UVL usually broadens and its lower energy tail overtakes GL. The peak energy of such DL emission was lower than those in lightly doped GaN:Mg due to the randomly fluctuating potentials. ${ }^{59}$ It should be noted that $[\mathrm{Mg}]$ of 3 to $4 \times 10^{19} \mathrm{~cm}^{-3}$ is routinely used to obtain a p-type GaN $\left(p=1 \times 10^{18} \mathrm{~cm}^{-3}\right)$ hole-injecting layer in light-emitting devices, and the emergence of blue luminescence (BL) band at $300 \mathrm{~K}$ in Fig. 10(d) is a fingerprint of p-type conductivity of $\mathrm{GaN}: \mathrm{Mg}$.

Uedono et al. ${ }^{30}$ have studied vacancy-type defects in GaN:Mg films fabricated on FS-GaN substrates by MOVPE using the PAS method. They have concluded that $\left[\mathrm{V}_{\mathrm{Ga}}\right]$ in GaN:Mg films with $[\mathrm{Mg}]$ lower than $2 \times 10^{18} \mathrm{~cm}^{-3}$ was comparable to or lower than that in UID GaN before and after activation annealing. ${ }^{11,30}$ However, the effects of the change in $E_{\mathrm{F}}$ on the charge state of $\mathrm{V}_{\mathrm{Ga}}$-related defects, which modifies the $\mathrm{e}^{+}$trapping probability, have not been considered for analyzing $\left[\mathrm{V}_{\mathrm{Ga}}\right]$ from $S$ in p-type $\mathrm{GaN}^{30}$
Nevertheless, GaN:Mg films with $[\mathrm{Mg}]$ of $4 \times 10^{19} \mathrm{~cm}^{-3}$ has been concluded to contain multiple vacancies such as $\mathrm{V}_{\mathrm{Ga}}\left(\mathrm{V}_{\mathrm{N}}\right)_{2}$ or $\mathrm{V}_{\mathrm{Ga}}\left(\mathrm{V}_{\mathrm{N}}\right)_{3}$, most probably $\mathrm{V}_{\mathrm{Ga}}\left(\mathrm{V}_{\mathrm{N}}\right)_{2}$, both before and after annealing. ${ }^{30}$ Although the defect concentration was slightly decreased by increasing the annealing temperature $\left(T_{\mathrm{a}}\right),{ }^{30}$ it was clearly higher than the detection limit of PAS being approximately a few times $10^{15} \mathrm{~cm}^{-3}$ (in n-type GaN). Because PAS is insensitive to positively charged or interstitial-type point defects ${ }^{8}$ such as $\mathrm{V}_{\mathrm{N}}$ and $\mathrm{Mg}$ interstitials, $\mathrm{GaN}: \mathrm{Mg}$ films of low $[\mathrm{Mg}]$ may contain certain amounts of $\mathrm{V}_{\mathrm{N}}$ owing to the Fermi-level effect ${ }^{15,20,58}$ and surface nonstoichiometry during the growth. ${ }^{21}$ The incorporation of $\mathrm{V}_{\mathrm{N}}$ likely results in weak but detectable GL and RL bands, as shown in Figs. 10(b)-10(d). By comparing Figs. 10(a)-10(c) and Fig. 10(d), it is obvious that NBE (UVL) emission intensity of the sample with $[\mathrm{Mg}]$ of $4 \times 10^{19} \mathrm{~cm}^{-3}$ is more than an order of magnitude lower than those of UID or lower $[\mathrm{Mg}]$ samples even at $10 \mathrm{~K}$. This result implies that the highest $[\mathrm{Mg}]$ sample contains higher concentration NRCs. Judging from Fig. 2, $N_{\mathrm{NRC}}$ of this particular sample is predicted to be higher than, at least, a few times $10^{16} \mathrm{~cm}^{-3}$. This concentration range agrees with that of unknown donors (or donor-type defects) obtained from temperature-variable Hall effect measurements ${ }^{60}$ on epitaxial GaN:Mg films of quite similar $[\mathrm{Mg}]$, which were grown on FS-GaN substrates manufactured by the same supplier (Mitsubishi Chemical Corp.). Such defects may act as NRCs as the energy level is higher than $E_{\mathrm{F}}$ of the p-type GaN:Mg sample. 
The Mg I/I drastically changed the electronic properties of $\mathrm{GaN}$, as follows. ${ }^{32}$ The top traces of Figs. $10(\mathrm{e})-10(\mathrm{~g})$ show the low-temperature PL spectra of $\mathrm{I} / \mathrm{I} \mathrm{GaN}: \mathrm{Mg}$ after annealing at $1300^{\circ} \mathrm{C}$. It is noted that all $\mathrm{I} / \mathrm{I}$ samples exhibited UVL band, and the result indicates successful formation of $\mathrm{Mg}_{\mathrm{Ga}}$ acceptors by using $\mathrm{I} / \mathrm{I}$ with subsequent annealing. This fact encourages to fabricate vertical and lateral current-flow power-switching transistors because the fabrication of p-type GaN by $\mathrm{I} / \mathrm{I}$ is generally very difficult till now. ${ }^{61-63}$ However, as revealed from Figs. 10(b)-10(g), the absolute intensities of the ABE peak and UVL band were more than two orders of magnitude lower than that of epitaxial $\mathrm{GaN}: \mathrm{Mg}$ films with comparable $[\mathrm{Mg}]$ even at $10 \mathrm{~K}$. In addition, GL band intensities of I/I samples were slightly higher than those of the epilayers, and eventually GL overtook UVL for the highest [Mg] sample, as shown in Fig. 10(g). These results indicate that $\mathrm{Mg}$ implantation generates high concentration NRCs and simultaneously increases the concentration of point defects relevant to GL, namely $\left[\mathrm{V}_{\mathrm{N}}\right] \cdot{ }^{58}$ According to the fact that $N_{\mathrm{NRC}}$ and $\left[\mathrm{V}_{\mathrm{N}}\right]$ increased simultaneously, NRCs in I/I $\mathrm{GaN}: \mathrm{Mg}$ and GL may have a common origin, $\mathrm{V}_{\mathrm{N}}$, whose concentration is sufficiently low in the epitaxial GaN:Mg films. Uedono et al. have examined I/I GaN:Mg ([Mg] $=4 \times 10^{19} \mathrm{~cm}^{-3}$ ) by using PAS method to find that I/I damage generates multiple vacancies, whose size is larger than that in the epitaxial GaN:Mg: ${ }^{30,31}\left(\mathrm{~V}_{\mathrm{Ga}}\right)_{m}\left(\mathrm{~V}_{\mathrm{N}}\right)_{n}$ clusters, where both $m$ and $n$ may be close to $3 .^{31}$ They also reported ${ }^{30}$ that the concentration of $\left(\mathrm{V}_{\mathrm{Ga}}\right)_{m}\left(\mathrm{~V}_{\mathrm{N}}\right)_{n}$ decreased with increasing $T_{\mathrm{a}}$. However, it did not recover either, and $S$ of I/I $\mathrm{GaN}: \mathrm{Mg}(0.453)$ was larger than that of epitaxial GaN:Mg films $(0.449)^{30}$ or $S_{\mathrm{DF}}(0.442)$. Accordingly, the present $\mathrm{I} / \mathrm{I}$ $\mathrm{GaN}: \mathrm{Mg}$ films likely contain high concentrations of $\left(\mathrm{V}_{\mathrm{Ga}}\right)_{3}\left(\mathrm{~V}_{\mathrm{N}}\right)_{3}$ clusters. ${ }^{30}$ Because SRH-type major intrinsic NRCs in n-type $\mathrm{GaN}$ are $\mathrm{V}_{\mathrm{Ga}} \mathrm{V}_{\mathrm{N}}$, the donor-type $\left(\mathrm{V}_{\mathrm{Ga}}\right)_{3}\left(\mathrm{~V}_{\mathrm{N}}\right)_{3}$ most likely acts as NRCs in compensated semi-insulating and p-type ${ }^{20} \mathrm{GaN}$.

In $4 \mathrm{H}-\mathrm{SiC}$, the origin of major intrinsic NRCs in n-type and p-type materials ${ }^{55}$ is the same, namely, $Z_{1 / 2}$ center, which has similar capture-cross-sections for an electron and a hole. ${ }^{56}$ However, in the case of GaN, the defect species of NRCs in n-type and p-type materials are different. Because the size of NRCs in GaN:Mg $\left[\mathrm{V}_{\mathrm{Ga}}\left(\mathrm{V}_{\mathrm{N}}\right)_{2}\right.$ in the epitaxial and $\left(\mathrm{V}_{\mathrm{Ga}}\right)_{3}\left(\mathrm{~V}_{\mathrm{N}}\right)_{3}$ in the $\left.\mathrm{I} / \mathrm{I} \mathrm{GaN}: \mathrm{Mg}\right]^{30,31}$ is larger than that in $\mathrm{n}-$ type material $\left(\mathrm{V}_{\mathrm{Ga}} \mathrm{V}_{\mathrm{N}}\right)$, their electron capture-cross-sections $\left(\sigma_{\mathrm{n}}\right)$ would be larger than $\sigma_{\mathrm{p}}$ of $\mathrm{V}_{\mathrm{Ga}} \mathrm{V}_{\mathrm{N}}\left(\sim 7 \times 10^{-14} \mathrm{~cm}^{2}\right){ }^{34}$ Because electron mobility is higher than hole mobility in $\mathrm{GaN}$, the NBE emission intensity in p-type $\mathrm{GaN}$ becomes significantly weaker than that in n-type material. As a matter of fact, $\tau_{\mathrm{PL}}$ of the NBE emission in GaN:Mg epilayer was significantly shorter than the n-type $\mathrm{GaN},{ }^{32}$ and the $\mathrm{I} / \mathrm{I}$ $\mathrm{GaN}: \mathrm{Mg}$ did not emit the NBE emission at room temperature, as shown in Figs. 10(e)-10(g).

\section{Nonradiative recombination centers in $\mathrm{Al}_{0.6} \mathrm{Ga}_{0.4} \mathrm{~N}$}

Because $E_{\mathrm{Form}}$ of $\mathrm{V}_{\mathrm{Al}}$ in AlN is very low and even negative $e^{20,22,23}$ in $n$-type materials, $\mathrm{V}_{\mathrm{Al}}$ has been found to be the major vacancy defects in AlN (Ref. 64) and $\mathrm{Al}_{\mathrm{x}} \mathrm{Ga}_{1-\mathrm{x}} \mathrm{N}$ alloys $(x \neq 0){ }^{65}$ Therefore, impacts of point defects

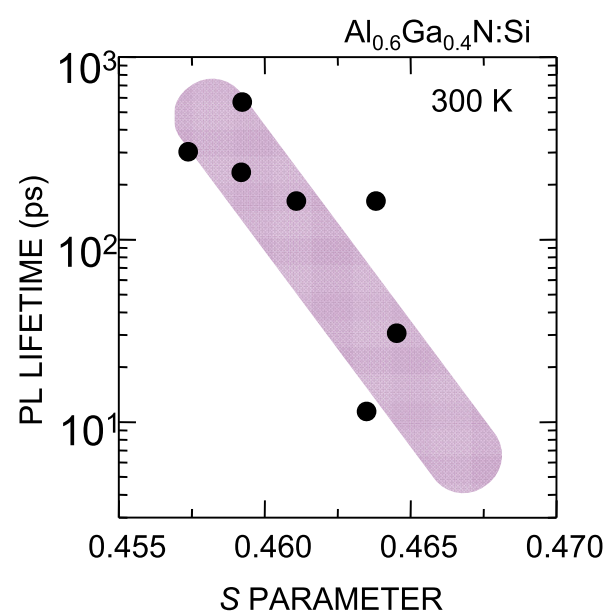

FIG. 11. $\tau_{\mathrm{PL}}-S$ relationship for the $\mathrm{Al}_{0.6} \mathrm{Ga}_{0.4} \mathrm{~N}: \mathrm{Si}$ films at various [Si]. [Reproduced with permission from J. Appl. Phys. 113, 213606 (2013). Copyright 2013 AIP Publishing LLC]. ${ }^{21}$

introduced by impurity doping on the recombination dynamics in $\mathrm{Al}_{\mathrm{x}} \mathrm{Ga}_{1-\mathrm{x}} \mathrm{N}$ must be studied carefully, as $\mathrm{V}_{\mathrm{Al}^{-}}$-complexes may also act as NRCs. It is noteworthy that significant correlation between $\tau_{1}$ and $S$ ( $\tau_{1}-S$ relation) seen in $\mathrm{GaN}$ is also remarkable in $\mathrm{Al}_{0.6} \mathrm{Ga}_{0.4} \mathrm{~N}: \mathrm{Si}$ films, as shown in Fig. 11. Almost linear $\tau_{1}-S$ relation indicates that the major NRCs in the $\mathrm{Al}_{0.6} \mathrm{Ga}_{0.4} \mathrm{~N}$ :Si films are most likely composed of $\mathrm{V}_{\mathrm{III}}$, such as $\mathrm{V}_{\mathrm{Al}} \mathrm{X}$ and $\mathrm{V}_{\mathrm{Ga}} \mathrm{X}$, because $\tau_{\mathrm{PL}}$ at room temperature is generally dominated by $\tau_{\mathrm{NR}}$. In analogy with n-type $\mathrm{GaN}, \mathrm{V}_{\mathrm{Al}} \mathrm{V}_{\mathrm{N}}$ and $\mathrm{V}_{\mathrm{Ga}} \mathrm{V}_{\mathrm{N}}$ divacancies are the most alarming culprits.

\section{CONCLUSION}

The limiting factors of $\tau_{\text {minority }}\left(\tau_{\mathrm{NR}}\right.$ of the NBE emission) in various quality n-type $\mathrm{GaN}, \mathrm{GaN}: \mathrm{Mg}$, and $\mathrm{Al}_{0.6} \mathrm{Ga}_{0.4} \mathrm{~N} ; \mathrm{Si}$ alloy films were investigated using timeresolved luminescence and PAS measurements. The roomtemperature $\tau_{\mathrm{NR}}$ in n-type GaN of a variety of TDD, growth orientations, polar directions, and polytypes, which were grown by various growth techniques, increased with the decrease in $\left[\mathrm{V}_{\mathrm{Ga}} \mathrm{V}_{\mathrm{N}}\right]$. The $\tau_{\mathrm{NR}}$ value also increased with the increase in $L_{+}$, and these results indicate that major intrinsic NRC is $\mathrm{V}_{\mathrm{Ga}} \mathrm{V}_{\mathrm{N}}$. From the relationship between $\tau_{\mathrm{NR}}$ and $N_{\mathrm{NRC}}$, its $\sigma_{\mathrm{p}}$ was determined as $7 \times 10^{-14} \mathrm{~cm}^{2}$. The major NRCs in the epitaxial and I/I GaN:Mg are assigned to larger size multiple vacancy complexes such as $\mathrm{V}_{\mathrm{Ga}}\left(\mathrm{V}_{\mathrm{N}}\right)_{n}(\mathrm{n}=2$ or 3) and $\left(\mathrm{V}_{\mathrm{Ga}}\right)_{3}\left(\mathrm{~V}_{\mathrm{N}}\right)_{3}$, respectively. In analogy with $\mathrm{GaN}$, major NRCs in $\mathrm{Al}_{0.6} \mathrm{Ga}_{0.4} \mathrm{~N}$ alloys are assigned to vacancy complexes containing $\mathrm{V}_{\mathrm{III}}$ such as $\mathrm{V}_{\mathrm{Al}} \mathrm{V}_{\mathrm{N}}$ and $\mathrm{V}_{\mathrm{Ga}} \mathrm{V}_{\mathrm{N}}$ divacancies.

\section{ACKNOWLEDGMENTS}

The authors thank Professors H. Miyake and K. Hiramatsu for sharing the $\mathrm{Al}_{0.6} \mathrm{Ga}_{0.4} \mathrm{~N}: \mathrm{Si}$ samples with Professor A. Uedono. They wish to thank Dr. T. Koida, Dr. T. Onuma, Dr. K. Hazu, Dr. Y. Ishikawa, Dr. K. Furusawa, Dr. K. Shima, and T. Ohtomo for help with the optical measurements. This work was supported by the Council for Science, Technology, and Innovation (CSTI), Cross-ministerial Strategic Innovation 
Promotion Program (SIP), "Next-generation power electronicsResearch and Development of Fundamental Technologies for GaN Vertical Power Devices" (funding agency: NEDO) and Research Program of "Dynamic Alliance for Open Innovation Bridging Human, Environment and Materials" in "Network Joint Research Center for Materials and Devices," JSPS KAKENHI Grant Nos. JP16H06424, JP16H06427, JP17H02907, and 17H04809 and Program for research and development of next-generation semiconductor to realize energy-saving society by MEXT, Japan.

${ }^{1}$ In the statement of Scientific Background on the Nobel Prize in Physics 2014, Efficient blue light-emitting diodes leading to bright and energysaving white light sources. Compiled by the Class for Physics of the Royal Swedish Academy of Sciences, October 7, 2014; I. Akasaki, Rev. Mod. Phys. 87, 1119 (2015); H. Amano, ibid. 87, 1133 (2015); S. Nakamura, ibid. 87, 1139 (2015); Introduction to Nitride Semiconductor Blue Lasers and Light Emitting Diodes, edited by S. Nakamura and S. F. Chichibu (Taylor \& Francis, London, 2000).

${ }^{2}$ S. Chichibu, T. Azuhata, T. Sota, and S. Nakamura, Appl. Phys. Lett. 69, 4188 (1996).

${ }^{3}$ Y. Narukawa, Y. Kawakami, S. Fujita, S. Fujita, and S. Nakamura, Phys. Rev. B 55, R1938 (1997).

${ }^{4}$ S. F. Chichibu, A. Uedono, T. Onuma, B. A. Haskell, A. Chakraborty, T. Koyama, P. T. Fini, S. Keller, S. P. DenBaars, J. S. Speck, U. K. Mishra, S. Nakamura, S. Yamaguchi, S. Kamiyama, H. Amano, I. Akasaki, J. Han, and T. Sota, Nat. Mater. 5, 810 (2006); Philos. Mag. 87, 2019 (2007).

${ }^{5}$ S. J. Pearton, J. C. Zolper, R. J. Shul, and F. Ren, J. Appl. Phys. 86, 1 (1999).

${ }^{6}$ D. Shibata, R. Kajitani, M. Ogawa, K. Tanaka, S. Tamura, T. Hatsuda, M. Ishida, and T. Ueda, in IEEE IEDM Technical Digest (2016), p. 248.

${ }^{7}$ T. Sugahara, H. Sato, M. Hao, Y. Naoi, S. Kurai, S. Tottori, K. Yamashita, K. Nishino, L. T. Romano, and S. Sakai, Jpn. J. Appl. Phys., Part 2 37, L398 (1998).

${ }^{8}$ R. Krause-Rehberg and H. S. Leipner, Positron Annihilation in Semiconductors, Solid-State Sciences (Springer, Berlin, 1999), Vol. 127.

${ }^{9}$ P. G. Coleman, Positron Beams and Their Application (World Scientific, Singapore, 2000).

${ }^{10}$ K. Saarinen, T. Laine, S. Kuisma, J. Nissilä, P. Hautojärvi, L. Dobrzynski, J. M. Baranowski, K. Pakula, R. Stepniewski, M. Wojdak, A. Wysmolek, T. Suski, M. Leszczynski, I. Grzegory, and S. Porowski, Phys. Rev. Lett. 79, 3030 (1997).

${ }^{11}$ A. Uedono, S. F. Chichibu, Z. Q. Chen, M. Sumiya, R. Suzuki, T. Ohdaira, T. Mikado, T. Mukai, and S. Nakamura, J. Appl. Phys. 90, 181 (2001).

${ }^{12}$ S. F. Chichibu, A. Uedono, T. Onuma, T. Sota, B. A. Haskell, S. P. DenBaars, J. S. Speck, and S. Nakamura, Appl. Phys. Lett. 86, 021914 (2005).

${ }^{13}$ S. F. Chichibu, K. Hazu, Y. Ishikawa, M. Tashiro, H. Namita, S. Nagao, K. Fujito, and A. Uedono, J. Appl. Phys. 111, 103518 (2012).

${ }^{14}$ T. Ogino and M. Aoki, Jpn. J. Appl. Phys., Part 1 19, 2395 (1980).

${ }^{15}$ J. Neugebauer and C. G. Van de Walle, Phys. Rev. B 50, 8067 (1994); Appl. Phys. Lett. 69, 503 (1996).

${ }^{16}$ J. L. Lyons, A. Janotti, and C. G. Van de Walle, Appl. Phys. Lett. 97, 152108 (2010).

${ }^{17}$ A. Y. Polyakov, N. B. Smirnov, A. S. Usikov, A. V. Govorkov, and B. V. Pushniy, Solid-State Electron. 42, 1959 (1998).

${ }^{18}$ V. A. Joshkin, C. A. Parker, S. M. Bedair, J. F. Muth, I. K. Shmagin, R. M. Kolbas, E. L. Piner, and R. J. Molnar, J. Appl. Phys. 86, 281 (1999).

${ }^{19}$ A. F. Wright, J. Appl. Phys. 90, 1164 (2001).

${ }^{20}$ C. G. Van de Walle and J. Neugebauer, J. Appl. Phys. 95, 3851 (2004).

${ }^{21}$ S. F. Chichibu, H. Miyake, Y. Ishikawa, M. Tashiro, T. Ohtomo, K. Furusawa, K. Hazu, K. Hiramatsu, and A. Uedono, J. Appl. Phys. 113, 213506 (2013); S. F. Chichibu, H. Miyake, Y. Ishikawa, K. Furusawa, and K. Hiramatsu, Appl. Phys. Lett. 107, 121602 (2015).

${ }^{22}$ T. Mattila and R. Nieminen, Phys. Rev. B 54, 16676 (1996).

${ }^{23}$ C. Stampfl and C. G. Van de Walle, Phys. Rev. B 65, 155212 (2002).

${ }^{24}$ A. Van Veen, H. Schut, M. Clement, J. M. M. de Nijs, A. Kruseman, and M. R. Ijpma, Appl. Surf. Sci. 85, 216 (1995).

${ }^{25}$ For example, see K. Fujito, S. Kubo, H. Nagaoka, T. Mochizuki, H. Namita, and S. Nagao, J. Cryst. Growth 311, 3011 (2009).
${ }^{26}$ K. Fujito, K. Kiyomi, T. Mochizuki, H. Oota, H. Namita, S. Nagao, and I. Fujimura, Phys. Status Solidi A 205, 1056 (2008).

${ }^{27}$ Y. Tsukada, Y. Enatsu, S. Kubo, H. Ikeda, K. Kurihara, H. Matsumoto, S. Nagao, Y. Mikawa, and K. Fujito, Jpn. J. Appl. Phys. Part 1 55, 05 FC01 (2016).

${ }^{28}$ Y. Mikawa, T. Ishinabe, S. Kawabata, T. Mochiduki, A. Kojima, Y. Kagamitani, and H. Fujisawa, Proc. SPIE 9363, 936302 (2015).

${ }^{29}$ K. Kojima, Y. Tsukada, E. Furukawa, M. Saito, Y. Mikawa, S. Kubo, H. Ikeda, K. Fujito, A. Uedono, and S. F. Chichibu, Appl. Phys. Express 8, 095501 (2015); Jpn. J. Appl. Phys., Part 1 55, 05FA03 (2016).

${ }^{30}$ A. Uedono, S. Takashima, M. Edo, K. Ueno, H. Matsuyama, H. Kudo, H. Naramoto, and S. Ishibashi, Phys. Status Solidi B 252, 2794 (2015).

${ }^{31}$ A. Uedono, S. Takashima, M. Edo, K. Ueno, H. Matsuyama, W. Egger, T. Koschine, C. Hugenschmidt, M. Dickmann, K. Kojima, S. F. Chichibu, and S. Ishibashi, "Carrier Trapping by Vacancy-Type Defects in MgImplanted GaN Studied Using Monoenergetic Positron Beams," Phys. Status Solidi B (published online).

${ }^{32}$ K. Kojima, S. Takashima, M. Edo, K. Ueno, M. Shimizu, T. Takahashi, S. Ishibashi, A. Uedono, and S. F. Chichibu, Appl. Phys. Express 10, 061002 (2017).

${ }^{33}$ Y. Shimahara, H. Miyake, K. Hiramatsu, F. Fukuyo, T. Okada, H. Takaoka, and H. Yoshida, Jpn. J. Appl. Phys., Part 1 50, 095502 (2011).

${ }^{34}$ S. F. Chichibu, K. Kojima, A. Uedono, and Y. Sato, Adv. Mater. 29, 1603644 (2017).

${ }^{35}$ M. Merano, S. Sonderegger, A. Crottini, S. Collin, P. Renucci, E. Pelucchi, A. Malko, M. H. Baier, E. Kapon, B. Deveaud, and J. D. Ganière, Nature 438, 479 (2005).

${ }^{36}$ P. Corfdir, P. Lefebvre, J. Levrat, A. Dussaigne, J.-D. Ganière, D. Martin, J. Ristić, T. Zhu, N. Grandjean, and B. Deveaud-Plédran, J. Appl. Phys. 105, 043102 (2009).

${ }^{37}$ Y. Ishikawa, M. Tashiro, K. Hazu, K. Furusawa, H. Namita, S. Nagao, K. Fujito, and S. F. Chichibu, Appl. Phys. Lett. 101, 212106 (2012).

${ }^{38}$ K. Furusawa, Y. Ishikawa, M. Tashiro, K. Hazu, S. Nagao, H. Ikeda, K. Fujito, and S. F. Chichibu, Appl. Phys. Lett. 103, 052108 (2013).

${ }^{39}$ S. Ishibashi, T. Tamura, S. Tanaka, M. Kohyama, and K. Terakura, Phys. Rev. B 76, 153310 (2007).

${ }^{40}$ S. Ishibashi and A. Uedono, J. Phys.: Conf. Ser. 505, 012010 (2014).

${ }^{41}$ P. E. Blöchl, Phys. Rev. B 50, 17953 (1994).

${ }^{42}$ G. Kresse and D. Joubert, Phys. Rev. B 59, 1758 (1999).

${ }^{43}$ J. P. Perdew, K. Burke, and M. Ernzerhof, Phys. Rev. Lett. 77, 3865 (1996).

${ }^{44}$ E. Boronski and R. M. Nieminen, Phys. Rev. B 34, 3820 (1986).

${ }^{45}$ A. Uedono, S. Ishibashi, T. Ohdaira, and R. Suzuki, J. Cryst. Growth 311, 3075 (2009).

${ }^{46}$ K. Kojima, H. Ikeda, K. Fujito, and S. F. Chichibu, Appl. Phys. Lett. 111, 032111 (2017); K. Kojima, T. Ohtomo, K. Ikemura, Y. Yamazaki, M. Saito, H. Ikeda, K. Fujito, and S. F. Chichibu, J. Appl. Phys. 120, 015704 (2016).

${ }^{47}$ J. Feldmann, G. Peter, E. O. Göbel, P. Dawson, K. Moore, C. Foxon, and R. J. Elliot, Phys. Rev. Lett. 59, 2337 (1987).

${ }^{48}$ H. Akiyama, S. Koshiba, T. Someya, K. Wada, H. Noge, Y. Nakamura, T. Inoshita, A. Shimizu, and H. Sakaki, Phys. Rev. Lett. 72, 924 (1994).

${ }^{49}$ K. Kawakami, T. Nakano, and A. A. Yamaguchi, Proc. SPIE 9748 , 97480S (2016).

${ }^{50}$ C. A. Klein, J. Appl. Phys. 39, 2029 (1968).

${ }^{51}$ T. Onuma, Y. Kagamitani, K. Hazu, T. Ishiguro, T. Fukuda, and S. F. Chichibu, Rev. Sci. Instrum. 83, 043905 (2012).

${ }^{52}$ T. Aggerstam, A. Pinos, S. Marcinkevicius, M. Linnarsson, and S. Lourdudodd, J. Electron. Mater. 36, 1621 (2007).

${ }^{53}$ M. A. Reshchikov and H. Morkoç, J. Appl. Phys. 97, 061301 (2005).

${ }^{54}$ A. Alkauskas, Q. Yan, and C. G. Van de Walle, Phys. Rev. B 90, 075202 (2014).

${ }^{55}$ K. Danno, D. Nakamura, and T. Kimoto, Appl. Phys. Lett. 90, 202109 (2007).

${ }^{56}$ I. D. Booker and T. Kimoto, in Europe Conference on Silicon Carbide and Related Materials 2016 (Halkidiki, Greece, 2016), No. Tu2a.01.

${ }^{57}$ N. T. Son, X. T. Trinh, L. S. Løvlie, B. G. Svensson, K. Kawahara, J. Suda, T. Kimoto, T. Umeda, J. Isoya, T. Makino, T. Ohshima, and E. Janzén, Phys. Rev. Lett. 109, 187603 (2012).

${ }^{58}$ M. A. Reshchikov, D. O. Demchenko, J. D. McNamara, S. F. Carrido, and R. Calarco, Phys. Rev. B 90, 035207 (2014).

${ }^{59}$ L. Eckey, U. Gfug, J. Holst, A. Hoffmann, A. Kaschner, H. Siegle, C. Thomsen, B. Schineller, K. Heime, M. Heuken, O. Schön, and R. Beccard, J. Appl. Phys. 84, 5828 (1998). 
${ }^{60}$ M. Horita, S. Takashima, R. Tanaka, H. Matsuyama, K. Ueno, M. Edo, T. Takahashi, M. Shimizu, and J. Suda, Jpn. J. Appl. Phys., Part 1 56, 031001 (2017).

${ }^{61}$ T. Oikawa, Y. Saijo, S. Kato, T. Mishima, and T. Nakamura, Nucl. Instrum. Methods Phys. Res., Sect. B 365, 168 (2015).

${ }^{62}$ T. Narita, T. Kachi, K. Kataoka, and T. Uesugi, Appl. Phys. Express 10, 016501 (2017)

${ }^{63}$ T. Niwa, T. Fujii, and T. Oka, Appl. Phys. Express 10, 091002 (2017).

${ }^{64}$ A. Uedono, S. Ishibashi, S. Keller, C. Moe, P. Cantu, T. M. Katona, D. S. Kamber, Y. Wu, E. Letts, S. A. Newman, S. Nakamura, J. S. Speck, U. K.
Mishra, S. P. DenBaars, T. Onuma, and S. F. Chichibu, J. Appl. Phys. 105, 054501 (2009); S. F. Chichibu, T. Onuma, K. Hazu, and A. Uedono, Appl. Phys. Lett. 97, 201904 (2010).

${ }^{65}$ T. Onuma, S. F. Chichibu, A. Uedono, T. Sota, P. Cantu, T. M. Katona, J. F. Keading, S. Keller, U. K. Mishra, S. Nakamura, and S. P. DenBaars, J. Appl. Phys. 95, 2495 (2004); S. F. Chichibu, K. Hazu, T. Onuma, and A. Uedono, Appl. Phys. Lett. 99, 051902 (2011); A. Uedono, K. Tenjinbayashi, T. Tsutsui, Y. Shimahara, H. Miyake, K. Hiramatsu, N. Oshima, R. Suzuki, and S. Ishibashi, J. Appl. Phys. 111, 013512 (2012). 